\title{
The non-avian theropod quadrate I: standardized terminology with an overview of the anatomy and function
}

Christophe Hendrickx, Ricardo Araújo, Octávio Mateus

The quadrate of reptiles and most other tetrapods plays an important morphofunctional role by allowing the articulation of the mandible with the cranium. In Theropoda, the morphology of the quadrate is particularly complex and varies importantly among different clades of non-avian theropods, therefore conferring a strong taxonomic potential. Inconsistencies in the notation and terminology used in discussions of the theropod quadrate anatomy have been noticed, including at least one instance when no less than eight different terms were given to the same structure. A standardized list of terms and notations for each quadrate anatomical entity is proposed here, with the goal of facilitating future descriptions of this important cranial bone. In addition, an overview of the literature on quadrate function and pneumaticity ontogeny in non-avian theropods is presented, along with a discussion of the inferences that could be made from this research. Specifically, the quadrate of the large majority of non-avian theropods is akinetic but the diagonally oriented intercondylar sulcus of the mandibular articulation allowed both rami of the mandible to move laterally when opening the mouth in many of theropods. Pneumaticity of the quadrate is also present in most tetanuran clades and the pneumatic chamber-invaded by the quadrate diverticulum of the mandibular arch pneumatic system-was connected to one or several pneumatic foramina on the medial, lateral, posterior, anterior or ventral sides of the quadrate. 


\section{The non-avian theropod quadrate I: standardized terminology with}

\section{2 an overview of the anatomy and function}

4 Christophe Hendrickx ${ }^{1,2}$

$5 \quad$ 'Universidade Nova de Lisboa, CICEGe, Departamento de Ciências da Terra, Faculdade de

6 Ciências e Tecnologia, Quinta da Torre, 2829-516, Caparica, Portugal.

7 를 Museu da Lourinhã, 95 Rua João Luis de Moura, 2530-158, Lourinhã, Portugal.

8 chritophe.hendrickx@hotmail.com

Ricardo Araújo $0^{2,3,4,5}$

11 2ªseu da Lourinhã, 95 Rua João Luis de Moura, 2530-158, Lourinhã, Portugal.

$12{ }^{3}$ Huffington Department of Earth Sciences, Southern Methodist University, PO Box 750395, 13 75275-0395, Dallas, Texas, USA.

$14{ }^{4}$ Instituto Superior Técnico, Universidade de Lisboa, Av. Rovisco Pais 1, 1049-001, Lisboa, 15 Portugal.

16 5 Museum für Naturkunde, Invalidenstraße 43, 10115, Berlin, Germany.rmaraujo@smu.edu

18 Octávio Mateus ${ }^{1,2}$

19 'Universidade Nova de Lisboa, CICEGe, Departamento de Ciências da Terra, Faculdade de 20 Ciências e Tecnologia, Quinta da Torre, 2829-516, Caparica, Portugal.

$21 \quad{ }^{2}$ Museu da Lourinhã, 95 Rua João Luis de Moura, 2530-158, Lourinhã, Portugal.

22 omateus@fct.unl.pt 
ABSTRACT

25 The quadrate of reptiles and most other tetrapods plays an important morphofunctional role by

26 allowing the articulation of the mandible with the cranium. In Theropoda, the morphology of the

27 quadrate is particularly complex and varies importantly among different clades of non-avian

28 theropods, therefore conferring a strong taxonomic potential. Inconsistencies in the notation and

29 terminology used in discussions of the theropod quadrate anatomy have been noticed, including

30 at least one instance when no less than eight different terms were given to the same structure. A

31 standardized list of terms and notations for each quadrate anatomical entity is proposed here,

32 with the goal of facilitating future descriptions of this important cranial bone.

33 In addition, an overview of the literature on quadrate function and pneumaticity ontogeny

34 in non-avian theropods is presented, along with a discussion of the inferences that could be made

35 from this research. Specifically, the quadrate of the large majority of non-avian theropods is

36 akinetic but the diagonally oriented intercondylar sulcus of the mandibular articulation allowed

37 both rami of the mandible to move laterally when opening the mouth in many of theropods.

38 Pneumaticity of the quadrate is also present in most tetanuran clades and the pneumatic

39 chamber — invaded by the quadrate diverticulum of the mandibular arch pneumatic system — was

40 connected to one or several pneumatic foramina on the medial, lateral, posterior, anterior or

41 ventral sides of the quadrate. 
43 The quadrate (in Latin quadratum, meaning 'square') is a cranial bone of endochondral origin

44 that articulates with the mandible in all gnathostomes except mammaliaforms, which have had

45 the quadrate evolved into the incus (Reichert 1837; Takechi and Kuratani 2010; Brusatte 2012;

46 Benton 2015). In theropods, this bone plays many important functions such as a structural

47 support for the basicranium, articulatory element with the lower jaws, attachment for several

48 muscles, hearing, and hosting important nerves, pneumatic sinuses, and vascular passages (e.g.,

49 Witmer 1990, 1997; Bakker 1998; Sedlmayr 2002; Kundrát and Janáček 2007; Holliday and

50 Witmer 2008; Tahara and Larsson 2011; see Supplemental Information Appendix 1).

51 Although the outward morphology of the quadrate is relatively simple, it varies

52 significantly among theropods in the structure of its head, mandibular articulation, quadratojugal

53 contact and the presence of pneumatic openings, quadrate foramen, and lateral processes (e.g.,

54 Holtz 2003; Therrien et al. 2005; Hone and Rauhut 2010; Zanno and Makovicky 2011).

55 Variation in the quadrate morphology in the derived theropod group Aves has long been used as

56 a means of systematic significance (e.g., Lowe 1926; Samejima and Otsuka 1987; Barbosa 1990;

57 Elzanowski et al. 2001; Elzanowski and Stidham 2010). Similarly, but to a lesser degree, the

58 systematic potential of the quadrate bone has also been noted for non-avian theropods

59 (Maryańska and Osmólska 1997; Currie 2006), highlighting the importance that should be given

60 to the description of this bone in the literature on non-avian theropod anatomy. Nevertheless, the

61 terminology and abbreviations of the quadrate anatomy has been inconsistent in non-avian

62 theropods, and several different anatomical terms for the same quadrate sub-entity are often used

63 (see Supplemental Information Appendix 2). Although a list of anatomical terms has been given

64 by Baumel and Witmer (1993), Elzanowski et al. (2001) and Elzanowski and Stidham (2010) for 
65 the avian quadrate, the terminology proposed by these authors has not been applied to the

66 description of the non-avian theropod quadrate hitherto. Indeed, the quadrate of birds has greatly

67 changed in its morphology throughout the evolution of this clade and hence displays many

68 features absent in more primitive theropods. Thus, many anatomical terms coined by Baumel and

69 Witmer (1993), Elzanowski et al. (2001) and Elzanowski and Stidham (2010) cannot be applied

70 to the non-avian theropod quadrate. Moreover, some quadrate entities such as the quadrate

71 foramen and the lateral process observable in non-avian theropods are absent in their avian

72 descendants and do not appear in the list made by these authors.

73 The work presented here has two major aims. First, we propose a standardization of the

74 anatomical terms for the quadrate sub-units, each associated with a two to four letters

75 abbreviation and followed by a definition, in order to facilitate future descriptions of this bone in

76 the literature. Second, we present and discuss the current knowledge on the function and

77 pneumaticity of this important bone in non-avian theropods. A comprehensive study on the

78 anatomy and phylogenetic potential of the non-avian theropod quadrate through cladistic and

79 phylogenetic morphometric analyses will be provided in a companion article that will be

80 published later.

\section{Institutional Abbreviations}

83 AMNH, American Museum of Natural History, New York, U.S.A.; BHI, Black Hills Institute,

84 Hill City, South Dakota, USA; BYUVP, Brigham Young University Vertebrate Paleontology,

85 Provo, Utah, U.S.A.; CMNH, Carnegie Museum, Pittsburgh, Pennsylvania, U.S.A.; FMNH,

86 Field Museum of Natural History, Chicago, Illinois, U.S.A.; IGM, Mongolian Institute of

87 Geology, Ulaan Bataar, Mongolia; IVPP, Institute for Vertebrate Paleontology and 
Paleoanthropology, Beijing, China; MACN, Museo Argentino de Ciencias Naturales, Buenos Aires, Argentina; MCF PVPH, Museo Municipal Carmen Funes, Paleontologia de Vertebrados, Plaza Huincul, Argentina; MCNA, Museo de Ciencias Naturales y Antropológicas de Mendoza, Mendoza, Argentina; MIWG, Dinosaur Isle, Isle of Wight Museum Services, Sandown, U.K.; ML, Museu da Lourinhã, Lourinhã, Portugal; NCSM, North Carolina Museum of Natural Sciences, Raleigh, North Carolina, USA; MNHN, Muséum national d'Histoire Naturelle, Paris, France; MNA, Museum of Northern Arizona, Flagstaff, Arizona, USA; MNN, Musée National du Niger, Niamey, Niger; MPCA, Museo Provincial Carlos Ameghino, Cipolletti, Río Negro, Argentina; MSNM, Museo di Storia Naturale di Milano, Milan, Italy; MUCPv, Museo de Ciencias Naturales de la Universidad Nacional de Comahue, Neuquén, Argentina; NH, Horniman Museum \& Gardens, London, U.K.; NHM, The Natural History Museum, London, U.K.; OUMNH, Oxford University Museum, Oxford, U.K.; PVL, Fundación 'Miguel Lillo,' San Miguel de Tucumán, Argentina; PVSJ, Instituto y Museo de Ciencias Naturales, San Juan, Argentina; SMA, Sauriermuseum Aathal, Aathal, Switzerland; SMNS, Staatliches Museum für Naturkunde, Stuttgart, Germany; RTMP, Royal Tyrrell Museum of Palaeontology, Drumheller, Alberta, Canada; UCMP, University of California Museum of Paleontology, Berkeley, California, U.S.A.; UC, University of Chicago Paleontological Collection, Chicago, U.S.A.; UMNH, Utah Museum of Natural History, Salt Lake City, Utah, U.S.A.

\section{Theropod classification}

The theropod phylogeny adopted here follows the classification summarized by Hendrickx et al. (2015) for non-avian theropods. Megaraptoran theropods are here considered as belonging to the clade Allosauroidea, as proposed by Benson et al. (2010) and Carrano et al. (2012). The 
111 phylogenetic definitions of each non-avian theropod clade also follow those compiled and given

112 by Hendrickx et al. (2015): table 1).

113

PROPOSED TERMINOLOGY OF THE QUADRATE ANATOMY

\section{Favored terminology}

116 The anatomical terms of the theropod quadrate were grouped in five main sections: quadrate

117 body, quadrate head, mandibular articulation, pterygoid flange, and pneumatic openings. The

118 terms for each quadrate sub-units were selected by their relevance, significance and importance

119 in the non-avian theropod literature. The non-standardized traditional Romerian directional and

120 anatomical terms (Romer 1956; Wilson 2006) were, therefore, favored over the terminology of

121 the Nomina Anatomica Veterinaria (NAV) defined by the ICVGAN (2012) and the Nomina

122 Anatomica Avium (NAA) provided by Baumel (1993) as Romerian terms are the most commonly

123 used in the non-avian theropod literature (e.g., Eddy and Clarke 2011; pers. obs.). Consequently,

124 'anterior' and 'posterior' are used as directional terms in lieu of the veterinarian alternatives

125 'cranial' and 'caudal', respectively. Because non-avian archosaurs are the direct ancestors of

126 birds, Harris (2004) recommended to adopt the NAA as the standardized nomenclature to

127 describe all archosaurs (and even diapsids), yet we favor Wilson's (2006) opinion to retain

128 Romerian terms for non-avian dinosaurs. As noted by Wilson (2006), the Romerian

129 nomenclature is the lingua franca for most of the dinosaur/archosaur literature. In addition,

130 standard terminologies using Romerian terms are often proposed to describe the saurischian

131 anatomy (e.g., Hendrickx et al. in press; Wilson 1999; Wilson et al. 2011; Hendrickx and Mateus

132 2014). Comparison between the NAA nomenclature and the Romerian terminology here

133 proposed for the quadrate anatomy is provided in Figure and Table 1. 

to describe this bone in reptiles to six terms, namely: the main body, quadrate shaft, quadrate

136 foramen, quadrate head, quadrate flange and articular termination. Three terms were kept as such

137 in the proposed terminology of the quadrate (i.e., quadrate shaft, quadrate foramen, and quadrate

138 head) and the three others were slightly modified. The quadrate body (instead of "main body of

139 [the] quadrate" sensu Romer 1956: p. 640), mandibular articulation (instead of "articular

140 termination" sensu Romer 1956: p. 632) and pterygoid flange (instead of "quadrate flange" sensu

141 Romer 1956: p. 146) were chosen not only because they are more commonly used in the

142 theropod literature currently describing the quadrate (pers. obs.), but are also more specific of the

143 loci of the anatomical sub-entity described. It should be noted that the pterygoid flange of Romer

144 (1956) describes a wing-like process of the pterygoid and not the anteriorly projected ramus of

145 the quadrate.

\section{Figure 1}

\section{Table 1}

\section{Quadrate body}

149 Quadrate body (qb). Part of the quadrate that includes the quadrate shaft, the quadrate ridge, the

150 lateral contact (quadratojugal and/or squamosal contact), and the lateral process, and excludes

151 the quadrate head, mandibular articulation, and pterygoid flange (Figs. 1G, 2A). In posterior

152 view, the quadrate body is delimited by the lateral margin of the lateral contact and sometimes

153 by the medial margin of the quadrate foramen, the dorsal margin of the mandibular articulation,

154 the ventral margin of the quadrate head, and a medial margin mostly formed by the quadrate

155 shaft and the medial fossa of the pterygoid flange. The quadrate body is equivalent to the 
156 'Corpus ossis quadrati' of Baumel and Witmer (1993), and the 'Corpus quadrati' of Elzanowski

157 et al. (2001) and Elzanowski and Stidham (2010) for avian theropods (Fig. 1A).

158 Quadrate shaft (qs). Part of the quadrate body that excludes the lateral process and all

159 articulating surfaces (i.e., quadrate head, quadratojugal/squamosal/pterygoid contacts, and

160 mandibular articulation; Fig. 2C). The quadrate shaft, as called by Welles (1984), Sereno and

161 Novas (1994), Norell et al. (2006), Sampson and Witmer (2007), Sereno et al. (2008), Carrano et

162 al. (2011), Brusatte et al. (2012), and Choiniere et al. (2014a, b) is also referred as the 'quadrate

163 pillar' by Madsen and Welles (2000), and the 'ascending process' by Colbert (1989).

164 Quadrate ridge (qr). Ventrodorsally elongated column, ridge or crest located on the quadrate

165 body and visible in posterior view (Fig. 2C). Although the quadrate ridge is present in the large

166 majority of non-avian theropods, a description of the structure is often omitted in the literature.

167 The quadrate ridge is referred as 'a column' by Welles (1984), a 'ridge-like mediodorsal edge'

168 by Carr (1996), 'a prominent rounded ridge' by Smith et al. (2007), a 'columnar ridge' by

169 Rauhut et al. (2010), a 'robust ridge' by Brusatte et al. (2012), a 'ridge' or 'pillar' by Choiniere

170 et al. (2014a), and a 'bulging ridge' by Lautenschlager et al. (2014).

171 Quadrate ridge groove (qrg). Groove dividing the quadrate ridge in two different units at two-

172 thirds, or more dorsally, of the quadrate body height (Fig. 2G). A quadrate ridge groove exists in

173 some allosauroid theropods.

174 Quadrate foramen (qf). Aperture in the quadrate body or concavity on the lateral margin of the

175 quadrate body and delimited ventrally by the ventral quadratojugal contact and dorsally by the

176 dorsal quadratojugal contact and its ventral projection in some theropod taxa (Fig. 2A, E-G, I).

177 Most authors usually refer to this perforation as the quadrate foramen (e.g., Welles 1984; Sereno

178 and Novas 1994; Charig and Milner 1997; Maryańska and Osmólska 1997; Currie and Carpenter 
179 2000; Coria and Currie 2006; Currie 2006; Norell et al. 2006; Choiniere et al. 2010, 2014a, $b$;

180 Zanno 2010; Brusatte et al. 2012). Yet, it can be also called the 'paraquadratic foramen' (e.g.,

181 Barsbold and Osmólska 1999; Kobayashi and Lü 2003; Kobayashi and Barsbold 2005), the

182 'paraquadrate foramen' (Sampson and Witmer 2007; Dal Sasso and Maganuco 2011;

183 Lautenschlager et al. 2014), the 'paraquadrate fenestra' (Smith et al. 2007) or the 'quadrate

184 fenestra' (e.g., Carr 1996; Sereno et al. 1998; Currie 2003; Eddy and Clarke 2011). A quadrate

185 foramen exists in all non-avian theropods but Ceratosauria and Megalosauridae.

186 Lateral process (lpq). Lateral or anterolateral projection of the lateral margin of the quadrate

187 body (Fig. 2B). Also known as the 'dorsal wing' (Welles 1984; Currie 2006), the 'anterolateral

188 wing' (Madsen and Welles 2000), the 'lateral lamina' (Coria and Salgado 1998) and the 'lateral

189 ramus' (Sampson and Witmer 2007), this process can contact the quadratojugal and/or the

190 squamosal and therefore either be referred to the 'quadratojugal ramus' (Sampson and Witmer

191 2007) or the 'squamosal ramus' (Norell et al. 2006).

192 Quadratojugal contact (qje). Area of contact of the quadrate with the quadratojugal on the

193 lateral, anterolateral or, posterolateral margin of the quadrate body (Fig. 2G). The quadratojugal

194 contact, which is similar to the 'cotyla quadratojugalis' of Baumel and Witmer (1993),

195 Elzanowski et al. (2001) and Elzanowski and Stidham (2010) for avian theropods (Fig. 1B), can

196 be divided into a ventral and a dorsal quadratojugal contact when the quadrate foramen is present

197 and delimited by both quadrate and quadratojugal.

198 Ventral quadratojugal contact (vqje). Ventral area of contact of the quadrate with the

199 quadratojugal (Fig. 2B, F, H). The ventral quadratojugal contact of the quadrate always receives

200 the quadratojugal bone. 
201 Dorsal quadratojugal contact (dqje). Dorsal area of contact of the quadrate with the

202 quadratojugal (Fig. 2B, F). The ventral quadratojugal contact of the quadrate can either receive

203 the quadratojugal or both quadratojugal and squamosal in some theropod taxa.

204 Ventral projection of the dorsal quadratojugal contact (vpdq). Small projection of the dorsal

205 quadratojugal contact delimiting the laterodorsal margin of the quadrate foramen (Fig. 2I).

206 Dorsal projection of the ventral quadratojugal contact (dpvq). Small projection of the ventral

207 quadratojugal contact delimiting the lateroventral margin of the quadrate foramen.

208 Quadratojugal process (qjp). Anterior projection of the ventral quadratojugal contact of the

209 quadrate (Fig. 2B). Also known as the 'quadratojugal lamina' (Lautenschlager et al. 2014).

210 Lateroventral process (lvp)—Lateromedially oriented ventral projection of the ventral

211 quadratojugal contact of the quadrate that bounds the quadratojugal ventrally (Fig. 2H). The

212 lateroventral process is similar to the 'lateral process' of Maryańska and Osmólska (1997).

213 Squamosal contact (sqc). Contact on the lateral margin of the quadrate with the squamosal (Fig. 214 2B).

215 Posterior fossa (pfq). Depression or concavity situated on the posterior side of the quadrate

216 body and dorsal to the mandibular articulation, ventral to the quadrate head and lateral to the

217 quadrate ridge (Fig. 2B). The posterior fossa can include or exclude the quadrate foramen.

219 Quadrate head

220 Quadrate head (qh). Dorsal articulation of the quadrate abutting to the cotyle of the squamosal

221 and touching other bones of the braincase in some theropod taxa (Fig. 2D). The quadrate head, as

222 it is called by Britt (1991), Charig and Milner (1997), Madsen and Welles (2000), Sampson and

223 Witmer (2007), Sereno et al. (2008), Norell et al. (2009), Brusatte et al. (2012), Choiniere et al. 
$224(2014 a, b)$ and Lautenschlager et al. (2014) among others, has also been termed 'quadrate 225 cotylus' (Currie 2003; Coria and Currie 2006), 'quadrate cotyle' (Currie 2003; Coria and Currie 226 2006), ‘squamosal condyle' (Coria and Salgado 1998), 'squamosal articulation' (Turner et al. 227 2011), ‘dorsal articular surface' (Larson 2013), and 'otic process' (Maryańska and Osmólska 228 1997; Burnham 2004; Holliday and Witmer 2008). In avian theropods, the quadrate head is 229 homologous to the 'Caput quadrati' of Elzanowski et al. (2001) and Elzanowski and Stidham 230 (2010), and roughly equivalent to the 'Processus oticus' (Baumel and Witmer 1993). In birds, the 231 'Processus oticus' (Baumel and Witmer 1993), and the 'Pars oticus' of Elzanowski et al. (2001)

232 and Elzanowski and Stidham (2010) also includes several sub-units that are either absent in non233 avian theropods (e.g., Crista Tympanica, Tuberculum subcapitulare), or here included in the 234 quadrate body (e.g., Sulcus pneumaticus, Foramen pneumaticum rostromediale). The bistylic 235 quadrate head present in some tyrannosaurids, alvarezsauroids, oviraptorids and avian theropods 236 is divided into otic and squamosal capitula.

237 Otic capitulum (oca). Medial capitulum of the quadrate head articulating with the braincase 238 (Fig. 2H). The otic capitulum is referred as the 'capitulum (condylus) oticum' by Baumel and 239 Witmer (1993), Elzanowski et al. (2001) and Elzanowski and Stidham (2010) for avian 240 theropods (Fig. 1A).

241 Squamosal capitulum (sca). Lateral capitulum of the quadrate head articulating with the 242 squamosal (Fig. 2H). The squamosal capitulum is similar to the 'capitulum (condylus) 243 squamosum' of Baumel and Witmer (1993), Elzanowski et al. (2001) and Elzanowski and 244 Stidham (2010) for avian theropods (Fig. 1C).

245 Intercapitular sulcus (icas). Groove separating the ootic capitulum from the squamosal 246 capitulum on the dorsal surface of the quadrate head (Fig. 2H). The intercapitular sulcus (Witmer 
247 1990) is equivalent to the 'incisura intercapitularis' of Baumel and Witmer (1993), and the

248 'vallecula intercapitularis' of Elzanowski et al. (2001) and Elzanowski and Stidham (2010) for

249 avian theropods (Fig. 1E).

250

251 Mandibular articulation

252 Mandibular articulation (mar). Ventral surface of the quadrate, articulating with the mandible 253 and fitting into the glenoid fossa of the lower jaw. It includes the ectocondyle, entocondyles, 254 sometimes a mediocondyle, and a single intercondylar sulcus, even when three condyles are 255 present (Fig. 2C). The mandibular articulation, also known as the 'mandibular capitulum' 256 (Lautenschlager et al. 2014), is equivalent to the 'Processus mandibularis' of Baumel and 257 Witmer (1993), and 'Pars mandibularis' of Elzanowski et al. (2001) and Elzanowski and 258 Stidham (2010) for avian theropods (Fig. 1A). Although most authors (e.g., Currie 2006;

259 Sampson and Witmer 2007; Rauhut et al. 2010; Brusatte et al. 2012; Lautenschlager et al. 2014) 260 referred the ectocondyle and entocondyles as the lateral and medial condyles (or hemicondyles) 261 respectively, the terms ectocondyle and entocondyle have been used by Welles (1984), and 262 Madsen and Welles (2000). The condyle present in between the ecto- and entocondyles in some 263 theropods is here coined mediocondyle.

264 Ectocondyle (ecc). Lateral condyle of the mandibular articulation (Fig. 6.2). The ectocondyle is 265 equivalent to the 'condylus (mandibularis) lateralis' of Baumel and Witmer (1993), Elzanowski 266 et al. (2001) and Elzanowski and Stidham (2010) for avian theropods (Fig. 1F).

267 Entocondyle (enc). Medial condyle of the mandibular articulation. The entocondyle has been 268 referred as the 'condylus (mandibularis) medialis' by Baumel and Witmer (1993), Elzanowski et 269 al. (2001) and Elzanowski and Stidham (2010) for avian theropods (Fig. 1F). 
270 Mediocondyle (mdc). Posterior condyle of the mandibular articulation located between the ecto-

271 and entocondyles. The mediocondyle is referred as the 'third condyle' by Clark et al. (1994) and

$272 \mathrm{Xu}$ and $\mathrm{Wu}$ (2001), the 'accessory condyle' by Kobayashi and Lü (2003) and Lautenschlager et

273 al. (2014), and the 'condylus caudalis' of Baumel and Witmer (1993) and Elzanowski et al.

274 (2001) for avian theropods.

275 Intercondylar sulcus (ics). Groove separating the ectocondyle from the entocondyle and

276 articulated with the interglenoid ridge of the articular (Fig. 2E, K). The intercondylar sulcus, a

277 term also used by Carrano et al. (2011), can be referred as a 'groove' (e.g., Madsen 1976; Britt

278 1991; Madsen and Welles 2000; Currie 2006), 'swelling' (Charig and Milner 1997), 'sulcus'

279 (e.g., Kobayashi and Lü 2003; Norell et al. 2006; Sadleir et al. 2008), 'trochlea' (Brochu 2003;

280 Brusatte et al. 2010), 'trochlear surface' (Brusatte et al. 2010, 2012), and 'intercondylar bridge'

281 (Zanno 2010). The intercondylar sulcus is similar to the 'sulcus intercondylaris' (Baumel and

282 Witmer 1993) and the 'vallecula intercondylaris' (Elzanowski et al. 2001; Elzanowski and

283 Stidham 2010) of the quadrate of avian theropods (Fig. 1F).

284 Anterior intercondylar notch (ain). Notch located in between the ectocondyle and

285 entocondyle, on the anterior margin of the mandibular articulation (Fig. 2K).

286 Posterior intercondylar notch (pin). Notch located in between the ectocondyle and

287 entocondyle, on the posterior margin of the mandibular articulation, and being referred as the 288 'pit' by Bakker (1998) (Fig. 2J).

289 Figure 2

290

291 Pterygoid flange 
292 Pterygoid flange (pfl). Ventrodorsally elongated sheet-like process projecting anteriorly or 293 anteromedially from the medial side of the anterior surface of the quadrate body to contact the 294 pterygoid bone (Fig. 2A, D). The pterygoid flange, a term also used by Charig and Milner 295 (1997), Brochu (2003), Currie (2006), Coria and Currie (2006), Rauhut et al. (2010) and

296 Lautenschlager et al. (2014), is also known as the 'quadrate/anterior flange' (e.g., Colbert 1989;

297 Norell et al. 2006; Brusatte et al. 2010, 2012), the 'pterygoid ramus' (e.g., Sereno and Novas 298 1994; Sampson and Witmer 2007; Choiniere et al. 2010, 2014a, b), the 'pterygoid wing' (e.g., 299 Welles 1984; Madsen and Welles 2000; Eddy and Clarke 2011), the 'pterygoid ala' (e.g., Currie 300 2003, 2006; Sadleir et al. 2008; Dal Sasso and Maganuco 2011), the 'pterygoid process' (Molnar 301 1991; Carr 1996; Sereno et al. 2008), the 'optic wing' (Balanoff and Norell 2012), the 'orbital 302 process' (Clark et al. 1994; Chiappe et al. 2002), and the 'processus orbitalis' (Baumel and 303 Witmer 1993; Elzanowski et al. 2001; Elzanowski and Stidham 2010) for avian theropods (Fig. 304 1B).

305 Pterygoid contact (ptc). Area of contact with the pterygoid on the medial margin of the 306 pterygoid flange or the quadrate body (Fig. 2D). In avian theropods, the pterygoid contact is 307 homologous, to the 'facies pterygoidea' in Elzanowski et al. (2001) and the 'facies articularis 308 pterygoidea' in Elzanowski and Stidham (2010), as well as the 'condylus pterygoideus', located 309 on the quadrate body in Baumel and Witmer (1993), Elzanowski et al. (2001), and Elzanowski 310 and Stidham (2010; Fig. 1D).

311 Medial fossa (mfq). Depression or concavity located on the medial surface of the pterygoid

312 flange, typically on its posteroventral extremity (Fig. 2D). The medial fossa is delimited by the 313 quadrate shaft and the ventral shelf in some theropod taxa. The medial fossa is similar to the 
314 'fossa corporis quadrati' of Fuchs (1954) and the 'fossa basiorbitalis' of Elzanowski et al. (2001)

315 and Elzanowski and Stidham (2010) for avian theropods (Fig. 1D).

316 Ventral shelf (vsh). A medial or posteromedial fold of the ventral margin of the pterygoid flange

317 (Fig. 3A, G, M). The term 'shelf' was employed by Sereno and Novas (1994) and ventral shelf

318 was used by Sampson and Witmer (2007), Eddy and Clarke (2011) and Carrano et al. (2011).

Pneumatic foramina and fossae

321 Quadrate pneumatic chamber (qpc). Internal chamber within the quadrate, either fully

322 contained within the bone or communicating externally by one or several pneumatic foramina.

323 The quadrate pneumatic chamber hosts the quadrate sinus/diverticulum and, in some cases,

324 includes several interconnected chambers separated by thin bony lamellae within the quadrate

325 body and pterygoid flange (Kundrát and Janáček 2007; Tahara and Larsson 2011; Gold et al. 326 2013)..

327 Dorsal pneumatic foramen (dpf). Aperture located on the anterodorsal surface of the quadrate,

328 just ventral to the quadrate head.

329 Medial pneumatic foramen (mpf). Aperture or recess situated on the medial side of the

330 quadrate, typically in the ventral portion of the medial surface of the pterygoid flange (Fig. 5A-

331 D). The medial pneumatic foramen is homologous to the 'foramen pneumaticum' of Baumel and

332 Witmer (1993), and the 'foramen pneumaticum basiorbitale' of Elzanowski et al. (2001) and

333 Elzanowski and Stidham (2010) for avian theropods.

334 Posterior pneumatic foramen (ppf). Aperture or recess on the posterior surface of the quadrate

335 body, typically at mid-height of the quadrate (Figs. 2G, 5). The posterior pneumatic foramen is 
336 similar to and likely homologous to the 'foramen pneumaticum caudomediale' of Elzanowski

337 and Stidham (2010) for avian theropods (Fig. 1C).

338 Anterior pneumatic foramen (apf). Aperture or recess on the anterior surface of the quadrate

339 body, typically at mid-height of the quadrate (Fig. 5K). The anterior pneumatic foramen is likely

340 homologous to the 'foramen pneumaticum medial' of Elzanowski et al. (2001), and the 'foramen

341 pneumaticum rostromediale' of Elzanowski and Stidham (2010).

342 Ventral pneumatic foramen (vpf). Aperture or recess on the ventral surface of the quadrate.

343 The ventral pneumatic foramen is equivalent to the 'foramen pneumaticum adventitium' (or

344 ectopic pneumatic foramen) of Elzanowski and Stidham (2010) for avian theropods (Fig. 5I, J).

345 Posterior pneumatic fossa (ppfo). Shallow and well-delimited pneumatic recess on the

346 posterior surface of the quadrate body, at mid-height of the bone and medial to the quadrate

347 foramen (Fig. 5E).

348 Lateral pneumatic fossa (lpfo). Shallow and poorly-delimited pneumatic recess on the ventral

349 portion of the lateral surface of the quadrate, shortly dorsal to the ectocondyle (Fig. 5L).

351 Figure $3 \& 4$

\section{MORPHOLOGICAL VARIATION IN QUADRATE SUB-UNITS}

353 To establish comparisons between taxa with widely disparate quadrate morphology, a homology

354 concept of the feature in question is required. Here, we will give a general account of the

355 variability within different anatomical sub-units of the quadrate by following the criteria

356 summarized in Rieppel (2006) to establish inter-taxic topological homologies.

357 The quadrate ridge is easily distinguishable in many theropod taxa such as Dilophosaurus

358 wetherilli (Welles 1984; Fig. 3C), Aerosteon riocoloradensis (MCNA-PV 3137; Fig. 4C) and 
359 Proceratosaurus bradleyi (NHM R.4860) but the demarcation of this structure may be only

360 subtly developed, as in Noasaurus leali (PVL 4061), Majungasaurus crenatissimus (FMNH PR

361 2100; Fig. 3I), and Eustreptospondylus oxoniensis (OUMNH J.13558; Fig. 3U). The quadrate

362 ridge is developed as a 'columnar ridge' in many theropod taxa such as Dilophosaurus wetherilli

363 (Welles 1984), Allosaurus 'jimmadseni' (SMA 0005; Allosaurus 'jimmadseni’ sensu Chure

364 2000; Loewen 2010) and Eotyrannus lengi (MIWG 1997.550) but also forms a thin crest as in

365 Tyrannosauridae (AMNH 5027; Carr 1996; Brusatte et al. 2012). Although the ventral portion of

366 the quadrate ridge is usually demarcated just above the entocondyle of the mandibular

367 articulation, its dorsal termination is more variable. The dorsal termination can reach the

368 quadrate head like in Acrocanthosaurus atokensis (NCSM 14345) or flatten at the mid-height of

369 the quadrate such as in Albertosaurus sarcophagus (Currie 2003: fig. 10B). The quadrate ridge

370 can be divided into two ridges by a deep groove as in Allosaurus fragilis (AMNH 600) and

371 Allosaurus europaeus (ML 415). The quadrate ridge can also flare at the second dorsal third of

372 the quadrate, and reappears slightly more dorsally, as observed in some derived Spinosauridae

373 (Hendrickx et al. 2014). Likewise, the ventral portion of the quadrate ridge can also dichotomize

374 into two crests separated by a concavity such as in the tyrannosaurids Albertosaurus

375 sarcophagus, Daspletosaurus sp. (Currie 2003: figs. 10 and 28) and Tyrannosaurus rex (AMNH

376 5027).

377 The pterygoid flange (Fig. 2D, pfl) contacts the quadrate process of the pterygoid

378 anteriorly or anteromedially, and sometimes other bones such as the epipterygoid in

379 Herrerasaurus ischigualastensis (Sereno and Novas 1994) and possibly Incisivosaurus (Balanoff

380 et al. 2009), the basisphenoid and prootic in Erlikosaurus andrewsi (Clark et al. 1994;

381 Lautenschlager et al. 2014), and the squamosal in Khaan mckennai (Balanoff and Norell 2012). 
382 Although the pterygoid flange can be easily homologized between taxa, it may acquire

383 subtrapezoidal, subtriangular, subrectangular and M-shaped outlines, or form a large semi-oval

384 structure. The ventral limit of the flange can reach the mandibular condyles (e.g., Tyrannosaurus

385 rex, Baryonyx walkeri; Fig. 3P) or get attached to the quadrate body far above the mandibular

386 articulation (e.g., Majungasaurus crenatissimus; Fig. 3J). This structure can in some instances be

387 divided into two ridges delimited by a deep pneumatic foramen facing ventrally (e.g., Alioramus

388 altai; Fig. 6.4J; Tyrannosaurus rex FMNH PR2081). In anterior view, the pterygoid flange can

389 be straight and only projected anteriorly, as in the carcharodontosaurid Shaochilong maortuensis

390 (Brusatte et al. 2010: fig. 7a), or anteromedially recurved. The anteroventral margin of the

391 pterygoid flange can either be straight, or medially and/or dorsally deflected, forming a

392 horizontally oriented or dorsally inclined shelf-like structure here referred as the ventral shelf, as

393 in Majungasaurus crenatissimus (FMNH PR 2100; Fig. 3G), Carnotaurus sastrei (MACN-CH

394 894) and Allosaurus fragilis (Madsen 1976: plate 3d).

395 The medial fossa of the quadrate (Fig. 2D, mfq) is easily homologized between taxa as it

396 is always situated on the pterygoid flange, typically on its ventrodorsal surface. This fossa is

397 posteriorly delimited by the quadrate body in non-avian theropods and sometimes by the ventral

398 shelf of the pterygoid flange. The medial fossa can be of variable depth (deep in

399 Cryolophosaurus; FMNH PR1821; shallow in Eustreptospondylus; OUMNH J.13558),

400 pneumatized (e.g., Falcarius; UMNH VP 14559; Fig. 4P), and situated in the ventralmost part of

401 the pterygoid flange (e.g., Tsaagan; IGM 100-1015) or at mid-height of it and just above a large

402 pneumatic recess like in Mapusaurus roseae (MCF PVPH-108.102).

403 The posterior fossa of the quadrate (Fig. 2B, pfq) can be located either in between the

404 quadrate and the quadratojugal, being confluent with the quadrate foramen (e.g., Mapusaurus; 
405 MCF PVPH-108.102), or in the middle of the quadrate shaft and between the quadrate ridge and 406 the lateral limit of the quadrate shaft (e.g., 'Syntarsus'; MNA V2623), Tsaagan (Norell et al. 407 2006), Majungasaurus (Sampson and Witmer 2007; Fig. 3I). The posterior fossa can either be 408 strongly ventrodorsally elongated like in the carcharodontosaurid Acrocanthosaurus (NCSM 409 14345), or form an oval concavity lateromedially wide (e.g., Majungasaurus; Sampson and 410 Witmer 2007). Similarly to the medial fossa, the posterior fossa can host a pneumatic foramen 411 positioned dorsally (e.g., Sinornithomimus; IVPP V11797-10) or ventrally (e.g., Garudimimus;

412 IGM 100-13) inside the fossa.

413 Due to the highly variable morphology of the quadrate foramen, this structure deserves 414 special attention. It can be completely absent (e.g., Carnotaurus, Torvosaurus,

415 Eustreptospondylus; Fig. 3U), or form a very small aperture (e.g., 'Syntarsus'; Tykoski 2005) to 416 a large opening (e.g., Bambiraptor; Fig. 4T). In most non-avian theropods, only a small portion 417 of the lateral margin of the quadrate foramen is delimited by the quadratojugal (e.g., Sinraptor; 418 Currie 2006) while in some non-avian theropods the majority of the lateral margin is formed by 419 the quadratojugal (e.g., Dromaeosaurus). Finally, in a few theropods, the foramen can be 420 completely enclosed in the quadrate (e.g., Aerosteon; Sereno et al. 2008; Fig. 4C). The quadratojugal contact of the quadrate (Fig. 2G, qjc) can either be a single extensive 422 contact or made of two contacts separated by the quadrate foramen. In the latter case, the ventral 423 quadratojugal contact and the dorsal quadratojugal contact of the quadrate are not always clearly 424 separated and their dorsal and ventral margins, respectively, can overlap like in the sinraptorid 425 Sinraptor dongi (IVPP 10600). If the quadrate foramen is absent or fully enclosed by the 426 quadrate, the lateral quadratojugal contact typically forms an elongated line of variable width 427 along the lateral margin of the quadrate. Where separated by the quadrate foramen, the ventral 
428 and dorsal contacts can display a wide variety of surface and outlines. Both quadratojugal

429 contacts may face laterally, anteriorly or posteriorly, and their articulating surface can be smooth,

430 irregular or deeply grooved by several radiating ridges, as in Allosaurus fragilis (Madsen 1976).

431 The ventral quadratojugal contact is typically D-shaped or ovoid in lateral view. Its anterior

432 margin can extend far anteriorly, forming the quadratojugal process (Norell et al. 2006), and its

433 ventral margin can project far laterally, as in Oviraptoridae (Maryańska and Osmólska 1997).

434 The dorsal quadratojugal contact can vary from a very thin line to a broad surface in lateral or

435 posterior views and its dorsal extension can reach the dorsal condyle or terminate well beneath it.

436 A ventral projection of this contact may be present, and such projection delimiting part of the

437 lateral border of the quadrate can either be short, like in Daspletosaurus sp. (Currie 2003: fig.

438 28A) and Baryonyx walkeri (Fig. 3O), or form an elongated ramus, like in the therizinosaurid

439 Falcarius utahensis (Zanno 2010: fig. 1H) and the coelurosaur Zuolong salleei (Choiniere et al.

440 2010: fig. 3B).

441 In some basal theropods, ceratosaurs and dromaeosaurids, the lateral process of the

442 quadrate (Fig. 2B, lpq) forms a wing-like projection similar to the pterygoid flange. This process

443 is an extension of the quadrate body laterally so it is difficult to delimit. Such process is present

444 in Allosaurus 'jimmadseni' (SMA 0005), Sinraptor dongi (Currie 2006: fig. 1D), and

445 Erlikosaurus andrewsi (Clark et al. 1994: fig. 7). The lateral process can also vary in shape and

446 size, as it is lateromedially short and parabolic in posterior view (e.g., Carnotaurus; MACN-CH

447 894), or lateromedially elongated and subtriangular in posterolateral view (e.g., Dilophosaurus;

448 UCMP 37302; Fig. 3B). Its ventral border can also extend to the quadrate foramen (e.g.,

449 Bambiraptor; AMNH 30556; Fig. 4T) or more ventrally, sometimes reaching the medial condyle 
450 of the mandibular articulation (e.g., Ilokelesia, Majungasaurus; MCF PVPH 35, FMNH PR 451 2100; Fig. 3I).

452 The quadrate head always articulates with the cotylus of the squamosal and more rarely

453 with other bones of the braincase such as the opisthotic in oviraptorids (Maryańska and

454 Osmólska 1997), the prootic in Mononykus olecranus (Perle et al. 1994; Chiappe et al. 2002) and

455 the postorbital in Shuvuuia deserti (Chiappe et al. 1998, 2002). The contact between the quadrate

456 and the opistothic-exoccipital/paroccipital process is also present in Herrerasaurus

457 ischigualastensis (Sereno and Novas 1994), Dilophosaurus wetherilli (Welles 1984),

458 Ceratosaurus magnicornis (Madsen and Welles 2000; Sanders and Smith 2005), tyrannosaurids

459 (Currie 2003), Heyuannia huangi (Lü 2005), and Erlikosaurus andrewsi (Lautenschlager et al.

460 2014), yet this contact occurs on a small medial surface just immediately dorsal to the quadrate

461 head and not with the quadrate head itself. The large majority of non-avian theropods have a

462 monostylic quadrate head (Rauhut 2003; pers. obs.); yet, oviraptorids (Maryańska and Osmólska

463 1997: fig. 3B), the alvarezsaurid Shuvuuia deserti (Chiappe et al. 1998), and some

464 tyrannosaurids such as Tyrannosaurus and Gorgosaurus (Larson 2013) have the apomorphic

465 condition of possessing a bistylic quadrate head. In those theropods, the otic capitulum of the

466 quadrate head always contacts the braincase. This condition has also been observed in the

467 dromaeosaurid Mahakala omnogovae (Turner et al. 2007) but Turner et al. (2011: fig. 4) later

468 reconsidered the head of the quadrate as not being bistylic. The morphology of the quadrate head

469 is variable in dorsal view; it may be subtriangular in most basal theropods (Sereno and Novas

470 1994) like Dilophosaurus (UCMP 37302; Fig. 3E), Erlikosaurus (Lautenschlager et al. 2014)

471 and Bambiraptor (AMNH 30556; Fig. 4V), oval to subcircular in megalosaurids like Afrovenator

472 (UC OBA1) and Torvosaurus (BYUVP 9246), and allosauroids such as Aerosteon (MCNA-PV- 
473 3137; Fig. 4E), Sinraptor (IVPP 10600) and Shaochilong (IVPP V2885.3) or subquadrangular in

474 some Spinosaurinae such as Irritator (SMNS 58022). While the dorsal surface of the quadrate

475 head is either convex or flattened in posterior view in most non-avian theropods, the quadrate

476 head of some allosaurids (Bakker 1998: fig. 5C) and derived tyrannosaurids (FMNH PR208)

477 shows a well-marked concavity on the dorsal margin. The quadrate head can also be conical in

478 posterior view, as in Oviraptoridae (Maryańska and Osmólska 1997: fig. 1B). Despite this

479 variability, the quadrate head can be easily homologized inter-taxically due to the obvious

480 location of this structure.

481 With the exception of the therizinosaur Erlikosaurus andrewsi and the ornithomimosaur

482 Sinornithomimus dongi which both seem to have an autapomorphical tricondylar condition on

483 the mandibular articulation (Clark et al. 1994; Kobayashi and Lü 2003; Lautenschlager et al.

484 2014), all other non-avian theropods have two mandibular condyles. The presence of three

485 mandibular condyles was also noted in the alvarezsaurid Avimimus portentosus (Chatterjee 1995)

486 and the dromaeosaurid Sinornithosaurus millenii (Xu and Wu 2001). However, Vickers-Rich et

487 al. (2002) only found two condyles in Avimimus and our observations confirm that the third

488 condyle of Sinornithosaurus seems to be part of the much broader lateral condyle (Xu and $\mathrm{Wu}$

489 2001: fig. 4D).

490 The intercondylar sulcus (Fig. 2E, ics) varies in orientation, size and depth. It can be

491 large, shallow and sub-perpendicular to the long axis passing through the mandibular articulation

492 as in Tyrannosaurus rex (FMNH PR2081), or narrow, deep and strongly lateromedially-oriented

493 as in some derived spinosaurids (e.g., MHNM.KK376).

494 In posterior view, the shape of the mandibular articulation (Fig. 2C, mar) can vary from

495 the biconvex condition known in most theropods, to the W-shaped articulation typical of Citipati 
496

497

498

499

500

501

502

503

504

505

506

507

508

509

510

511

512

513

514 515

516

517 518

osmolskae (Clark et al. 2002: fig. 6) or a single convex articulation seen in some dromaeosaurids such as Tsaagan mangas (IGM 100/1015). In Tsaagan, the convex outline of the mandibular articulation in posterior view results from a poor delimitation of the ecto- and entocondyle and the separation of these two condyles by a shallow intercondylar sulcus; yet this morphology might be due to poor preservation of the mandibular condyle. A posterior intercondylar notch (Fig. 2J, pin) was observed in Allosaurus (Bakker 1998: fig. 5B, C; SMA 0005) and Suchomimus tenerensis (MNN GAD 502) whereas an anterior intercondylar notch (Fig. 2K, ain) is present in the abelisaurids Majungasaurus crenatissimus (FMNH PR 2100; Fig. 3L) and Carnotaurus sastrei (MACN-CH 894). Pneumaticity of the quadrate can be externally expressed by pneumatic foramina or restricted to an internal chamber within the quadrate bone. The establishment of inter-taxic homologies is difficult to assess because these structures have very diverse interspecific variability. Nevertheless, as in other saurischian taxa (Schwarz et al. 2007), these pneumatic structures have phylogenetic signal (e.g., Gold et al. 2013; Hendrickx et al. 2014; see below). These openings can appear on different sides and portions of the quadrate. The medial and posterior pneumatic foramina (Fig. 2G, ppf) usually occur in the medial and posterior fossa respectively, and their position inside these fossae is quite variable. Pneumatic foramina can also be located in a pneumatic recess outside the medial fossa and just beneath it such as in the carcharodontosaurids Mapusaurus roseae (Coria and Currie 2006) and Acrocanthosaurus atokensis (Eddy and Clarke 2011). In the latter, the pneumatic aperture is divided by a septum. 


\section{Function of the Quadrate}

520 In all archosaurs, and all amniotes except Mammaliaformes, the main function of the quadrate is

521 the articulation of the cranium with the mandible, yet this bone also play an important role in the

522 mobility of the skull in many extant theropods. Streptostyly is a fundamental property of all

523 avian theropods, and quadrate kinesis in birds, known already in the beginning of the $19^{\text {th }}$

524 century (Nitzsch 1816), has been extensively studied over the past sixty years (e.g., Fisher 1955;

525 Bock 1964, 1999, 2000; Bühler 1981; Zusi 1984, 1993; Bühler et al. 1985, 1988; Chatterjee

526 1991, 1997; Hoese and Westneat 1996; Zweers et al. 1997; Zweers and Vanden Berge 1998;

527 Bout and Zweers 2001; Gussekloo and Bout 2005; Meekangvan et al. 2006). Streptostyly

528 consists of the rotation of the quadrate at its dorsal articulation against the squamosal which

529 typically lead to a transverse movement, although a lateral movement of the quadrate around an

530 anteroposteriorly directed axis occurs in some lepidosaur taxa (Metzger 2002). Cranial kinesis in

531 avian theropods with a streptostylic quadrate includes upward (protraction) and downward

532 (retraction) rotation of the rostrum relative to the braincase. Three main types of kinesis, in

533 which the role of the quadrate is relatively equivalent, are recognized relative to the position of

534 the dorsal flexion zone of the cranium and the nature of the nasal opening in modern theropods

535 (Bock 1964; Bühler 1981; Zusi 1984; Meekangvan et al. 2006). In prokinesis, flexion occurs at

536 the nasofrontal joint and the upper jaw thereby moves as one unit; in amphikinesis, flexion

537 occurs in two zones of flexibility and the upper jaw and its tip are bent upward in

538 rhynchokinesis, flexion occurs forward from the nasofrontal joint, allowing its anterior part to be

539 moved (Zusi 1984).

540 Inference of the cranial kinesis and quadrate mobility in non-avian theropods has been

541 investigated by Holliday and Witmer (2008) which regard the cranium of this group of dinosaurs 
542 as partially kinetically competent, because synovial joints and protractor muscles are present, but

543 not fully kinetic like in birds. The strong suture of the quadrate to the quadratojugal and the

544 immobile contact of the quadrate and the pterygoid on the medial side of the pterygoid flange in

545 most non-avian theropods seem to indicate a limited movement, and perhaps even the total

546 absence of movement within the cranium. Although the synovial quadrate head joint existing in

547 theropods, and all other archosaurs, is necessary to infer cranial kinesis, its presence in akinetic

548 taxa such as crocodiles demonstrates that the synovial joint cannot be considered alone as an

549 argument for cranial kinesis. Synovial joints have actually been interpreted as growth zones

550 rather than articular surfaces of mobile joints based on the presence of very thin articular

551 cartilage covering the end of this joint (Holliday and Witmer 2008). According to Holliday and

552 Witmer (2008) "articular cartilage persists in loading environments that exert hydrostatic

553 pressures (which result in a change in volume but not shape) but exert low shear stresses".

554 Indeed, one of the key centers of deformation during normal biting is the quadrate-squamosal

555 contact, which would have experienced large shear stresses associated with torque and

556 asymmetrical loading during biting (Rayfield 2005), and the presence of a minimal amount of

557 cartilage between the quadrate and squamosal would therefore suggest that the synovial zone

558 was rather a growth zone than a mobile one. A streptostylic quadrate in Tyrannosaurus rex

559 (Molnar 1991, 1998), Nanotyrannus lancensis (Larson 2013), Oviraptor philoceratops (Smith

560 1992), Heyuannia huangi (Lü 2005) and Dromiceiomimus brevitertius (Russell 1972) based on the

561 saddle joint between the quadrate and squamosal only is therefore unlikely.

562 Nevertheless, and more convincingly, a streptostylic quadrate was also proposed in the

563 alvarezsaurid Shuvuuia deserti by Chiappe et al. (1998). In this taxon, the quadratojugal/jugal?

564 (n.b., Dufeau (2003) considers the quadratojugal to be absent in Shuvuuia deserti), instead of 
565 being firmly sutured to the quadrate as in other non-avian theropods, would have contacted the

566 lateral surface of the quadrate through a movable joint (Chiappe et al. 1998, 2002; see

567 Supplemental Information Fig. S3). According to Chiappe et al. (1998), the absence of a

568 laterodorsal contact of the quadrate with the quadratojugal/jugal, as well as a lateroventral

569 process of the squamosal, would have permitted the quadrate to pivot anteroposteriorly, and the

570 upper jaw to rotate ventrodorsally due to this transversal movement. These authors have implied

571 the existence of a bending zone between the frontals and the nasal-preorbital bones in $S$. deserti,

572 allowing the flexion of the snout as a single unit when the quadrate displaced forward, like in

573 prokinetic birds. Nevertheless, the complex contacts between the nasal, frontal and prefrontal

574 illustrated by Sereno (2001: fig. 12B) makes assessment of Chiappe et al.'s (1998) hypothesis

575 dubious (Holliday and Witmer 2008). Holliday and Witmer (2008) also note that the

576 maxillojugal and palatal flexion zones necessary to allow a true prokinesis in alvarezsaurids are

577 still not clearly defined. Likewise, the contact between the pterygoid flange of the quadrate and

578 the pterygoid also needs to be better documented in order to imply any specific movement of the

579 quadrate inside the cranium of $S$. deserti.

580 A movable articulation between the quadrate and quadratojugal was proposed in the

581 oviraptosaurids Heyuannia huangi (Lü 2003) and Nemegtomaia huangi (Lü et al. 2004, 2005). In

582 Heyuannia, the quadrate and quadratojugal articulation forms a trochlea-like structure (Lü 2003,

583 2005), while the quadratojugal contact of Nemegtomaia is diagnostically convex and was

584 described as a lateral cotyle by Lü et al. (2004). Although such articulation suggests some

585 mobility between the quadrate and quadratojugal, it is unlikely that the skull of these two

586 oviraptorids could display avian-like kinesis. As in other non-avian theropods, the oviraptorid

587 quadrate was an immovable bone (Barsbold 1977; Maryańska and Osmólska 1997) so that the 
588 quadratojugal, if kinetic, could only pivot either ventrodorsally or mediolaterally from the

589 quadratojugal contact of the quadrate. Yet, the quadratojugal of at least Nemegtomaia does not

590 seem to have a loose articulation with the jugal given that the articulating surface between the

591 two bones is anteroposteriorly extensive (Lü et al. 2004: fig. 2), disallowing mobility between

592 the jugal and quadratojugal. Consequently, we consider unlikely that movement was possible

593 between the quadrate and quadratojugal in Heyuannia and Nemegtomaia and, unlike Barsbold

594 (1977), see the oviraptorosaur skull as akinetic.

595 Quadrate articulation with the mandible and orientation of the intercondylar sulcus are

596 highly variable among non-avian theropods, therefore suggesting some variation in the

597 movement of the mandibular rami when the jaw opened. The helical intercondylar sulcus present

598 in many non-avian theropods (pers. obs.) was noticed by Bakker (1998) in basal theropod

599 dinosaurs, by Hendrickx and Buffetaut (2008) in spinosaurids, and by Molnar (1991) and Larson

600 (2008) in Tyrannosaurus rex. These authors suggested that the spiral groove of the mandibular

601 articulation constrained the diagonal ridge of the articular glenoid fossa, which fitted into the

602 intercondylar sulcus, to slide laterally. This would force the mandibular rami of the mandible to

603 displace laterally when the lower jaw was depressed, enlarging the width of the larynx in order to

604 swallow large-size prey items (Hendrickx and Buffetaut 2008).

605 In Allosaurus, the enlargement of the mandibular condyles associated with the

606 posteroventral inclination of the ventral part of the quadrate, and the intercondylar notch, were

607 interpreted by Bakker (1998) as joint-stabilization zones. According to Bakker (1998), the

608 anteroposterior enlargement of the articulating surface would improve the stability of the

609 mandibular articulation when the mouth was widely opened, whereas the intercondylar notch,

610 morphologically convergent to the depression of knee joints in crocodiles and birds, would be 
611 hosting one or several ligaments within the quadrate-mandibular articulation (Bakker 1998). An

612 intercondylar notch is present in the abelisaurids Carnotaurus sastrei (MACN-CH 894) and

613 Majungasaurus crenatissimus (FMNH PR 2100), and the spinosaurid Suchomimus tenerensis

614 (MNN GAD 502), perhaps implying similar jaw mechanics of the mandibular articulation as in

615 Allosaurus. Yet, Bakker (1998)'s jaw mechanics hypotheses based on the shape of the

616 mandibular articulation and the presence of an intercondylar notch require further investigation

617 with modern functional analysis methods such as FEA to be tested.

618

619 Figure 5 \& 6

620 Pneumaticity in the Quadrate

621 Pneumatization of the quadrate bone has long been recognized for its phylogenetic value (e.g.,

622 Gauthier 1986; Holtz 1998; Chiappe 2001; Rauhut 2003; Holtz et al. 2004; Smith et al. 2007;

623 Benson 2010; Carrano et al. 2012; Turner et al. 2012; Novas et al. 2013; Choiniere et al. 2014b).

624 Pneumatic foramina of the quadrate are widespread among avetheropod clades (Gold et al. 2013;

625 Fig. 4). The presence of one or several pneumatic foramina has indeed been recorded in

626 carcharodontosaurids (e.g., Coria and Currie 2006; Eddy and Clarke 2011), megaraptorans

627 (Sereno et al. 2008), tyrannosauroids (e.g., Molnar 1991; Brochu 2003; Currie 2003; Xu et al.

628 2004; Witmer and Ridgely 2010; Brusatte et al. 2012; Gold et al. 2013), compsognathids (Currie

629 and Chen 2001), alvarezsauroids (Choiniere pers. comm.), therizinosauroids (Clark et al. 1994;

630 Zanno 2010), oviraptorids (e.g., Maryańska and Osmólska 1997; Lü 2003; Kundrát and Janáček

631 2007; Balanoff and Norell 2012), ornithomimosaurs (e.g., Witmer 1997; Tahara and Larsson

632 2011), dromaeosaurids (Makovicky et al. 2005) and troodontids (Barsbold et al. 1987; Currie and

633 Zhao 1993; Varricchio 1997; Xu et al. 2002; Xu and Norell 2004). An incipient development of 
634 a pneumatic recess, the posterior pneumatic fossa, also exists in the basal allosauroid Sinraptor

635 dongi (Currie 2006), suggesting that quadrate pneumaticity may be an avetheropod

636 synapomorphy. Yet, external manifestation of quadrate pneumaticity only occurs in derived

637 members of Allosauroidea, Tyrannosauroidea, and Ornithomimosauria and an apneumatic

638 quadrate exists in the basal members of each of these clades (i.e., Sinraptor and Allosaurus for

639 Allosauroidea (Currie 2006); pers. obs., Tanycolagreus and Proceratosaurus for

640 Tyrannosauroidea (Carpenter et al. 2005; Rauhut et al. 2010), and Nqwebasaurus for

641 Ornithomimosauria; see Choiniere et al. (2012) codings of their datamatrix). Pneumatic foramina

642 have not been reported for any alvarezsauroid taxa, but are present in basalmost members of

643 Therizinosauria, Oviraptorosauria and Paraves. This suggests that external quadrate pneumaticity

644 occurred independently in several basal avetheropod clades and is a possibly synapomorphy of

645 the clade Therizinosauria + Pennaraptora (Fig. 6).

646 The pneumatic opening is particularly large in some allosauroids such as Aerosteon

647 riocoloradensis (Sereno et al. 2008; Fig. 5F) and Acrocanthosaurus atokensis (Eddy and Clarke

648 2011; Fig. 5A), and the therizinosaur Falcarius utahensis (Zanno 2010; Fig. 5D). It, however,

649 forms a small rounded or oval aperture lodged in the posterior fossa of the quadrate body in most

650 avetheropods (Fig. 5). The posterior pneumatic foramen is the most common quadrate pneumatic

651 aperture in non-avian theropods and is seen in many coelurosaur clades. For instance, it is

652 present in the tyrannosauroid Dilong paradoxus (Xu et al. 2004), the compsognathid

653 Sinosauropteryx prima (Currie and Chen 2001: fig. 3f), the ornithomimids Hexing qingyi (the

654 'quadratic foramen' of Liyong et al. 2012), Garudimimus brevipes (the 'foramen' of Kobayashi

655 and Barsbold 2005; Fig. 5G), Sinornithomimus dongi (the 'quadratic foramen' of Kobayashi and

656 Lü 2003) and Struthiomimus altus (AMNH 5339), the basal oviraptorosaur Incisivorosaurus 
657 gauthieri (Balanoff et al. 2009), the dromaeosaurid Buitreraptor gonzalezorum (Makovicky et al.

658 2005; Fig. 5H), and the troodontids Mei long (Xu and Norell 2004), Sinovenator changii (Xu et

659 al. 2002) and possibly Gobivenator mongoliensis (Tsuihiji et al. 2014). The posterior pneumatic

660 foramen is, in fact, incorrectly interpreted by several authors as the quadrate foramen in

661 ornithomimosaurs (e.g., Kobayashi and Lü 2003; Kobayashi and Barsbold 2005; Choiniere et al.

662 2012). A genuine quadrate foramen between the quadrate and quadratojugal, as seen in the large

663 majority of other theropods, is found in most (possibly all) ornithomimosaurs possessing a

664 posterior pneumatic foramen (e.g., Garudimimus, Struthiomimus; Kobayashi and Barsbold 2005;

665 pers. obs.). Tahara and Larsson (2011) wrote that "no obvious foramen or fossa was identified on

666 the posterior surface of the quadrate" in Ornithomimus edmontonicus. Yet, a deep posterior fossa

667 seems to be present on the right side of the specimen they studied (TMP 95-110-1; n.b., the fossa

668 seems to be filled with sediment on the left side), in the homologous position of that of the

669 posterior fossa of other ornithomimosaurs (pers. obs.). It is, therefore, surprising that this fossa

670 was apneumatic, as implied by Tahara and Larsson (2011). Consequently, we consider likely that

671 a posterior pneumatic foramen was also leading to the pneumatic chamber hosting the quadrate

672 diverticulum in this taxon. An incipient development of a posterior pneumatic foramen is seen in

673 Sinraptor dongi in which the quadrate, though apneumatic, includes a well-delimited pneumatic

674 fossa between the quadrate foramen and quadrate ridge (Currie 2006; Fig. 5E). The presence of a

675 posterior pneumatic foramen is a possible synapomorphy of the clade Pennaraptora, which

676 encompasses Oviraptorosauria and Paraves (Foth et al. 2014; Fig. 6). The medial pneumatic

677 foramen, located in the ventral corner of the pterygoid flange, has also been reported in several

678 theropod clades. It is present in the carcharodontosaurids Acrocanthosaurus atokensis (Eddy and

679 Clarke 2011; Fig. 5A), Mapusaurus roseae (Coria and Currie 2006; Fig. 5B), and 
680 Giganotosaurus carolinii (MUCPv-CH-1; Fig. 5C), the tyrannosaurids Albertosaurus

681 sarcophagus (Currie 2003: fig. 10B) and Tyrannosaurus rex (Molnar 1991; Brochu 2003), the

682 therizinosauroid Falcarius utahensis (Zanno 2010; Fig. 5D), the oviraptosaurids Conchoraptor

683 gracilis and possibly Ajancingenia yanshini (Maryańska and Osmólska 1997; Kundrát and

684 Janáček 2007), and the basal avialan Archaeopteryx lithographica (Domínguez Alonso et al.

685 2004). A pneumatic foramen has also been noticed in the mediodorsal part of the quadrate in the

686 ornithomimosaur Ornithomimus edmontonicus (Tahara and Larsson 2011). A pneumatic foramen

687 piercing the quadrate medially is a probable synapomorphic feature of Carcharodontosauridae or

688 carcharodontosaurids more derived than Concavenator corcovatus and/or Eocarcharia dinops,

689 pending on the results of the latest phylogenetic analyses on carcharodontosaurids (i.e., Ortega et

690 al. 2010; Carrano et al. 2012). In non-avian theropods, the ventral pneumatic foramen that occurs

691 within a recess on the posteroventral part of the pterygoid flange ('funnel-like external opening

692 on the rostral surface of the quadrate, above the condyles' of Gold et al., 2013: p. 37) is only

693 present in Tyrannosauroidea. It is observed in the tyrannosaurids Alioramus altai (Brusatte et al.

694 2012; Gold et al. 2013; Fig. 5I), Daspletosaurus sp. (Currie 2003: fig. 28C) and Tyrannosaurus

695 rex (Brochu 2003; Witmer and Ridgely 2010; Fig. 5J). In non-tyrannosaurid tyrannosauroids,

696 such a ventral pneumatic foramen is present in Dilong paradoxus (Gold et al. 2013) but was not

697 observed in the closely related taxa Guanlong wucaii, Proceratosaurus lengi, and

698 Xiongguanlong baimoensis (Gold et al. 2013). Yet, it is not clearly present in Eotyrannus lengi

699 (contra Gold et al. 2013; pers. obs.). A ventral pneumatic foramen of the quadrate is most likely

700 synapomorphic of non-proceratosaurid Tyrannosauroidea (Fig. 6). A pneumatic foramen can also

701 be seen on the anterior surface of the quadrate, as in Mapusaurus roseae (Coria and Currie 2006;

702 Fig. 5K), Heyuannia huangi (Lü 2005), Erlikosaurus andrewsi (Lautenschlager et al. 2014), 
703 Troodon formosus (Currie and Zhao 1993), and perhaps Tyrannosaurus rex (Molnar 1991). More

704 rarely, a pneumatic fossa can be situated on the lateral and posterior surface of the quadrate

705 body, as in Aerosteon riocoloradensis (MCNA-PV 3137; Fig. 5L) and Sinraptor dongi (Currie

706 2006; Fig. 5E), respectively. The presence of an anterior pneumatic foramen, a lateral pneumatic

707 fossa, or a posterior pneumatic fossa is an autapomorphy in each of these taxa.

708 Carcharodontosauridae (Coria and Currie 2006; Eddy and Clarke 2011) and

709 Tyrannosauridae (Molnar 1991; Brochu 2003) possess several pneumatic openings which

710 perforate different sides of the quadrate and sometimes intercommunicate (Brochu 2003). The

711 pneumatic foramina usually enter a large pneumatic chamber within the quadrate bone as in

712 Tyrannosaurus rex (Molnar 1991; Brochu 2003; Witmer and Ridgely 2010), Alioramus altai

713 (Gold et al. 2013), Conchoraptor gracilis (Kundrát and Janáček 2007) or Ornithomimus

714 edmontonicus (Tahara and Larsson 2011). The neovenatorid Aerosteon riocoloradensis also

715 possesses a large posterior pneumatic foramen leading to a pneumatic chamber, as well as a

716 shallow pneumatic recess on the lateral surface of the quadrate shaft (pers. obs.).

717 These pneumatic foramina and the pneumatic chamber associated with them are invaded

718 by the quadrate diverticulum of the mandibular arch pneumatic system which, together with the

719 periotic pneumatic system, forms the tympanic sinus of archosaurs (Dufeau 2011; Tahara and

720 Larsson 2011). The mandibular arch pneumatic system includes the quadrate and/or the articular

721 diverticulum which both have their embryological origins as parts of the first pharyngeal (=

722 mandibular) arch, like the middle ear sac itself (Witmer 1997). As in non-avian theropods, the

723 quadrate diverticulum of modern birds exhibits a large variety of morphologies, and can

724 pneumatize the quadrate by entering through a single medial or anteromedial foramen (Witmer

725 1990; Tahara and Larsson 2011). In basal theropods with an apneumatic quadrate, both medial 
726 and posterior fossae of the quadrate possibly represent the osteological trace of the quadrate

727 diverticulum. In non-avian theropods having a pneumatic quadrate, the position of the quadrate

728 diverticulum is variable as in ornithomimids (Tahara and Larsson 2011), carcharodontosaurids

729 and oviraptorids (pers. obs.). The quadrate diverticulum of non-avian theropods may also have

730 communicated with other diverticula such as the squamosal diverticulum as in Conchoraptor

731 gracilis (Kundrát and Janáček 2007), and the siphoneal diverticulum of the articular as in Dilong

732 paradoxus, Aerosteon riocoloradensis and perhaps other non-avian maniraptorans (Sereno et al.

733 2008; Tahara and Larsson 2011). In Tyrannosaurus rex, however, the siphoneal diverticulum

734 does not pass through the quadrate and the quadrate diverticulum only enters the ventral opening

735 of the pterygoid flange, and then passes with or without the siphoneal diverticulum along the

736 medial fossa of the pterygoid flange. Likewise, the quadrate diverticulum only pneumatizes two

737 distinct regions of the quadrate in Acrocanthosaurus atokensis and Mapusaurus roseae (Tahara 738 and Larsson 2011).

739

$740 \quad$ Figure 7

741

742

CONCLUSIONS

743 Here we propose a revised nomenclature of the quadrate bone and a corresponding set of

744 abbreviations that provide a standard set of terms for describing this cranial bone in non-avian

745 theropod dinosaurs. The quadrate can be divided into two regional categories - the quadrate

746 body and the pterygoid flange - and twelve anatomical sub-units - the quadrate shaft, quadrate

747 head, quadrate ridge, quadrate foramen, lateral process, quadratojugal contact, squamosal

748 contact, pterygoid contact, mandibular articulation, medial fossa, and posterior fossa. Although 
749 they are highly variable in shape, all quadrate entities, with perhaps the exception of the posterior

750 fossa, are easy to homologize across taxa, and a description of their morphology should be

751 provided in the literature.

752

The quadrate of the large majority of non-avian theropods is akinetic, and it is

753 unlikely that the streptostylic quadrate is present in the derived alvarezsauroids Shuvunia deserti,

754 as was previously thought. A lateral movement of the rami while the mandible was depressed

755 occurred in various theropods (e.g. spinosaurids). This lateral movement of the rami was due to a

756 helicoidal and diagonally oriented intercondylar sulcus of the mandibular articulation. The

757 presence of an intercondylar notch in allosaurids is interpreted as a joint-stabilization zone that

758 would improve the stability of the mandibular articulation when the mouth was widely opened.

759 However, this assumption needs further investigation from modern functional morphology

760 techniques.

761 A pneumatic quadrate is present in members of most non-avian avetheropod clades, in

762 which a pneumatic foramen is seen in the ventral part of the pterygoid flange and in the medial

763 and lateral fossae. Pneumatic foramina invading the quadrate seem to be independently acquired

764 by allosauroids, tyrannosaurids, compsognathids, and ornithomimosaurs throughout their

765 evolution. The presence of pneumatic foramina in the quadrate of basalmost members of

766 therizinosauroids, oviraptorids, troodontids and dromaeosaurids suggests that quadrate

767 pneumaticity is a synapomorphy of the clade Therizinosauria + Pennaraptora. Although the

768 pneumatic recess invaded by the quadrate diverticulum of the mandibular arch pneumatic system

769 is linked to a single pneumatic foramen in most avetheropods, the presence of several pneumatic

770 openings perforating different sides of the quadrate has been recorded in Megaraptora,

771 Carcharodontosauridae and Tyrannosauridae. 


\section{ACKNOWLEDGMENTS}

775

776

777

778

779

780

781

782

783

784

785

786

787

788

789

790

791

792

793

794

We thank editor Andrew Farke (Raymond M. Alf Museum of Paleontology) and reviewers Jonah Choiniere (Uni. Witwatersrand) and Federico Agnolin (MACN) who kindly provided insightful comments that greatly improved this paper. The quadrate of many non-avian theropods were examined first hand in several institutions and we thanks P. Sereno (Uni. Chicago), P. Makovicky (FMNH), W. Simpson (FMNH), M. Lamanna (CMNH), A. Henrici (CMNH), M. Carrano (NMNH), M. Brett-Surman (NMNH), S. Chapman (NHM), P. Barrett (NHM), P. Jeffery (OUMNH), S. Hutt (MIW), R. Allain (MNHN), R. Schoch (SMNS), H.-J. Siber (SMA), C. Dal Sasso (MSNM), A. Kramarz (MACN), F. Novas (MACN), R. Barbieri (MPCA), L. Salgado (MUCPv), J. Ignacio Canale (MUCPv-CH), R. Coria (MCF PVPH), C. Succar (MCF PVPH), J. Calvo (CePaLB), R. Martínez (PVSJ), C. Mehling (AMNH), M. Norell (AMNH), D. Krauze (SBU), J. Groenke (SBU), P. Brinkman (NCSM), and L. Zanno (NCSM) for access to specimens in their care. Photographs of theropod quadrates were kindly shared by M. Lamanna (CMNH), M. Ezcurra (MACN), R. Delcourt (Uni. São Paulo), M. Carrano (USNM), E. Buffetaut (CNRS), M. Ellison (AMNH), L. Witmer (Uni. Ohio), S. Brusatte (Uni. Edinburgh), R. Benson (Uni. Oxford), C. Foth (BSPG), P. Currie (Uni. Alberta), J. Canale (MUCPv-CH), P. Barrett (NHM), J. Choiniere (Uni. Witwatersrand), D. Eddy (Uni. Texas), P. Viscardi (Horniman), S. Nesbitt (Uni. Texas), Y. Kobayashi (HUM), R. Tahara (McGill Uni.), R. Pei (AMNH), C. Dal Sasso (MSNM), P. Sereno (Uni. Chicago), C. Abraczinskas (Uni. Chicago), N. Smith (Uni. Chicago), L. Zanno (FMNH), R. Tykoski (MNSD), D. Burnham (Uni. Kansas), P. Asaroff (MACN), R. Irmis (UMNH), V. Shneider (NCMNS), C. Brochu (Uni. 
795

796

797

798

799

800

801

802

803

804

805

806

807

808

809

810

811

812

813

814

815

816

817

818

819

820

821

822

823

824

825

826

827

828

829

830

Iowa), S. Lautenschlager (Uni. Bristol), M. Mortimer, K. Peyer (MNHN), and R. Molnar

(MNA), and the authors would like to address their sincere thanks to all of these people. We

acknowledge the use of Phylopic for the theropod silhouettes, and thank Scott Hartman,

Funkmonk, M. Martyniuk, and T. Michael Keesey for providing their artworks on Phylopic. A

special thank goes to Paolo Viscardi for taking photos of the ostrich quadrate at the Horniman

Museum \& Gardens, and D. Dufeau for sharing his MSc thesis on Shuvuuia. We also thank

Isabel Torres for giving a final check in the English. C.H. dedicates this paper to the memory of

Roger Bec.

\section{REFERENCES}

Bakker, R. T. 1998. Brontosaur killers: late Jurassic allosaurids as sabre-tooth cat analogues. Gaia 15: 145-158.

Balanoff, A. M. and Norell, M. A. 2012. Osteology of Khaan mckennai (Oviraptorosauria: Theropoda). Bulletin of the American Museum of Natural History 372: 1-77.

Balanoff, A. M., Xu, X., Kobayashi, Y., Matsufune, Y. and Norell, M. A. 2009. Cranial osteology of the theropod dinosaur Incisivosaurus gauthieri (Theropoda: Oviraptorosauria). American Museum Novitates 3651: 1-35.

Barbosa, A. 1990. Identification key of Iberian waders (Charadriiformes) based on the os quadratum. Miscellània Zoologica 14: 181-185.

Barsbold, R. 1977. Kinetism and peculiarity of the jaw apparatus of oviraptors (Theropoda, Saurischia). Soviet-Mongolian Paleontological Expedition, Trudy 4: 37-47 (In Russian).

Barsbold, R. and Osmólska, H. 1999. The skull of Velociraptor (Theropoda) from the Late Cretaceous of Mongolia. Acta Palaeontologica Polonica 44 (2): 189-219.

Barsbold, R., Osmólska, H. and Kurzanov, S. M. 1987. On a new troodontid (Dinosauria, Theropoda) from the Early Cretaceous of Mongolia. Acta Palaeontologica Polonica 32 (1-2): 121-132.

Baumel, J. J. 1993. Handbook of Avian Anatomy: Nomina Anatomica Avium. 2nd ed. Publications of the Nuttall Ornithological Club 23: 1-779.

Baumel, J. J. and Witmer, L. M. 1993. Osteologia. In: Baumel, J. J. (ed.), Handbook of Avian Anatomy: Nomina Anatomica Avium, 45-132. Nuttall Ornithological Club, Cambridge.

Benson, R., Carrano, M. and Brusatte, S. 2010. A new clade of archaic large-bodied predatory dinosaurs (Theropoda: Allosauroidea) that survived to the latest Mesozoic. Naturwissenschaften 97 (1): 71-78.

Benson, R. B. J. 2010. A description of Megalosaurus bucklandii (Dinosauria: Theropoda) from the Bathonian of the UK and the relationships of Middle Jurassic theropods. Zoological Journal of the Linnean Society 158 (4): 882-935. 
831

832

833

834

835

836

837

838

839

840

841

842

843

844

845

846

847

848

849

850

851

852

853

854

855

856

857

858

859

860

861

862

863

864

865

866

867

868

869

870

871

872

873

874

875

876

Benton, M. J. 2015. Vertebrate Palaeontology. Wiley-Blackwell, Chichester, West Sussex ; Hoboken, NJ, 480pp.

Bock, W. J. 1964. Kinetics of the avian skull. Journal of Morphology 114 (1): 1-41.

Bock, W. J. 1999. Avian cranial kinesis revisited. Acta Ornitologica 34 (2): 115-122.

Bock, W. J. 2000. The evolution of avian cranial kinesis. In: Zhou, Z. and Zhang, F. (eds.), Proceedings of the 5th Symposium of the Society of Avian Paleontology and Evolution, Beijing, 1-4 June 2000., Vol. 1, 191-201. Beijing, China.

Bout, R. G. and Zweers, G. A. 2001. The role of cranial kinesis in birds. Comparative Biochemistry and Physiology Part A: Molecular \& Integrative Physiology 131 (1): 197205.

Britt, B. B. 1991. Theropods of Dry Mesa Quarry (Morrison Formation, Late Jurassic), Colorado, with emphasis on the osteology of Torvosaurus tanneri. Brigham Young University Geology Studies 37: 1-72.

Brochu, C. A. 2003. Osteology of Tyrannosaurus rex: Insights from a nearly complete skeleton and high-resolution computed tomographic analysis of the skull. Society of Vertebrate Paleontology Memoir 7: 1-138.

Brusatte, S. L. 2012. Dinosaur Paleobiology. Wiley-Blackwell, 336pp.

Brusatte, S. L., Carr, T. D. and Norell, M. A. 2012. The osteology of Alioramus, a gracile and long-snouted tyrannosaurid (Dinosauria: Theropoda) from the Late Cretaceous of Mongolia. Bulletin of the American Museum of Natural History 366: 1-197.

Brusatte, S. L., Chure, D. J., Benson, R. B. J. and Xu, X. 2010. The osteology of Shaochilong maortuensis, a carcharodontosaurid (Dinosauria: Theropoda) from the Late Cretaceous of Asia. Zootaxa 2334: 1-46.

Bühler, P. 1981. Functional anatomy of the avian jaw apparatus. Form and function in birds 2: 439-468.

Bühler, P., Martin, L. D. and Witmer, L. M. 1988. Cranial kinesis in the Late Cretaceous birds Hesperornis and Parahesperornis. The Auk 105 (1): 111-122.

Bühler, P., Hecht, M. K., Ostrom, J. H., Viohl, G. and Wellnhofer, P. 1985. On the morphology of the skull of Archaeopteryx. The Beginnings of Birds: 135-140.

Burnham, D. A. 2004. New Information on Bambiraptor feinbergi (Theropoda: Dromaeosauridae) from the Late Cretaceous of Montana. In: Currie, P. J., Koppelhus, E. B., Shugar, M. A. and Wright, J. L. (eds.), Feathered Dragons: Studies on the Transition from Dinosaurs to Birds, 67-111. Indiana University Press, Bloomington, Indiana.

Carpenter, K., Miles, C. and Cloward, K. 2005. New small theropod from the Upper Jurassic Morrison Formation of Wyoming. In: Carpenter, K. (ed.), The Carnivorous Dinosaurs, 23-48. Indiana University Press, Bloomington, Indiana.

Carrano, M. T., Loewen, M. A. and Sertich, J. J. W. 2011. New materials of Masiakasaurus knopfleri Sampson, Carrano, and Forster, 2001, and implications for the morphology of the Noasauridae (Theropoda: Ceratosauria). Smithsonian Contributions to Paleobiology 95: 1-53.

Carrano, M. T., Benson, R. B. J. and Sampson, S. D. 2012. The phylogeny of Tetanurae (Dinosauria: Theropoda). Journal of Systematic Palaeontology 10 (2): 211-300.

Carr, T. D. 1996. Cranial osteology and craniofacial ontogeny of Tyrannosauridae (Dinosauria: Theropoda) from the Dinosaur Park Formation (Judith River Group, Upper Cretaceous, Campanian) of Alberta. MSc. Dissertation, University of Toronto, Toronto, Ontario, Canada, 358pp. 
877

878

879

880

881

882

883

884

885

886

887

888

889

890

891

892

893

894

895

896

897

898

899

900

901

902

903

904

905

906

907

908

909

910

911

912

913

914

915

916

917

918

919

920

921

Charig, A. J. and Milner, A. C. 1997. Baryonyx walkeri, a fish-eating dinosaur from the Wealden of Surrey. Bulletin of the Natural History Museum 53 (1): 11-70.

Chatterjee, S. 1991. Cranial anatomy and relationships of a new Triassic bird from Texas. Philosophical Transactions: Biological Sciences 332 (1265): 277-342.

Chatterjee, S. 1995. The Triassic bird Protoavis. Archaeopteryx 13: 15-31.

Chatterjee, S. 1997. The Rise of Birds: 225 Million Years of Evolution. Johns Hopkins University Press, Baltimore, Maryland, 312pp.

Chiappe, L. M. 2001. Phylogenetic relationships among basal birds. In: Gauthier, J. and Gall, L. F. (eds.), New Perspectives on the Origin and Early Evolution of Birds: Proceedings of the International Symposium in Honor of John H. Ostrom, 125-139. Yale Univ Peabody Museum.

Chiappe, L. M., Norell, M. A. and Clark, J. M. 1998. The skull of a relative of the stem-group bird Mononykus. Nature 392 (6673): 275-278.

Chiappe, L. M., Norell, M. A. and Clark, J. M. 2002. The Cretaceous, short-armed Alvarezsauridae: Mononykus and its kin. In: Chiappe, L. M. and Witmer, L. M. (eds.), Mesozoic Birds: Above the Heads of Dinosaurs, 87-120. University of California Press.

Choiniere, J. N., Forster, C. A. and de Klerk, W. J. 2012. New information on Nqwebasaurus thwazi, a coelurosaurian theropod from the Early Cretaceous Kirkwood Formation in South Africa. Journal of African Earth Sciences 71-72: 1-17.

Choiniere, J. N., Clark, J. M., Forster, C. A. and Xu, X. 2010. A basal coelurosaur (Dinosauria: Theropoda) from the Late Jurassic (Oxfordian) of the Shishugou Formation in Wucaiwan, People's Republic of China. Journal of Vertebrate Paleontology 30 (6): 1773-1796.

Choiniere, J. N., Clark, J. M., Norell, M. A. and Xu, X. 2014a. Cranial osteology of Haplocheirus sollers Choiniere et al., 2010 (Theropoda, Alvarezsauroidea). American Museum Novitates 3816: 1-44.

Choiniere, J. N., Clark, J. M., Forster, C. A., Norell, M. A., Eberth, D. A., Erickson, G. M., Chu, H. and Xu, X. 2014b. A juvenile specimen of a new coelurosaur (Dinosauria: Theropoda) from the Middle-Late Jurassic Shishugou Formation of Xinjiang, People's Republic of China. Journal of Systematic Palaeontology 12 (2): 177-215.

Chure, D. J. 2000. A new species of Allosaurus from the Morrison Formation of Dinosaur National Monument (Utah-Colorado) and a revision of the theropod family Allosauridae. Ph.D. Dissertation, Columbia University, New York, New York., 909pp.

Clark, J. M., Perle, A. and Norell, M. A. 1994. The skull of Erlicosaurus andrewsi, a late Cretaceous 'Segnosaur' (Theropoda, Therizinosauridae) from Mongolia. American Museum Novitates 3115: 1-39.

Clark, J. M., Norell, M. A. and Rowe, T. 2002. Cranial anatomy of Citipati osmolskae (Theropoda, Oviraptorosauria), and a reinterpretation of the holotype of Oviraptor philoceratops. American Museum Novitates 3364: 1-24.

Colbert, E. H. 1989. The Triassic dinosaur Coelophysis. Museum of Northern Arizona Bulletin 57: 1-174.

Coria, R. A. and Salgado, L. 1998. A basal Abelisauria Novas, 1992 (Theropoda-Ceratosauria) from the Cretaceous of Patagonia, Argentina. Gaia 15: 89-102.

Coria, R. A. and Currie, P. J. 2006. A new carcharodontosaurid (Dinosauria, Theropoda) from the Upper Cretaceous of Argentina. Geodiversitas 28 (1): 71-118. 
922

923

924

925

926

927

928

929

930

931

932

933

934

935

936

937

938

939

940

941

942

943

944

945

946

947

948

949

950

951

952

953

954

955

956

957

958

959

960

961

962

963

964

965

966

Currie, P. J. 2003. Cranial anatomy of tyrannosaurid dinosaurs from the Late Cretaceous of Alberta, Canada. Acta Palaeontologica Polonica 48 (2): 191-226.

Currie, P. J. 2006. On the quadrate of Sinraptor dongi (Theropoda: Allosauroidea) from the Late Jurassic of China. Mesozoic and Cenozoic Vertebrates and Paleoenvironments. Tributes to the career of Prof. Dan Grigorescu: 111-115.

Currie, P. J. and Zhao, X.-J. 1993. A new troodontid (Dinosauria, Theropoda) braincase from the Dinosaur Park Formation (Campanian) of Alberta. Canadian Journal of Earth Sciences 30 (10): 2231-2247.

Currie, P. J. and Carpenter, K. 2000. A new specimen of Acrocanthosaurus atokensis (Theropoda, Dinosauria) from the Lower Cretaceous Antlers Formation (Lower Cretaceous, Aptian) of Oklahoma, USA. Geodiversitas 22 (2): 207-246.

Currie, P. J. and Chen, P. 2001. Anatomy of Sinosauropteryx prima from Liaoning, northeastern China. Canadian Journal of Earth Sciences 38 (12): 1705-1727.

Dal Sasso, C. and Maganuco, S. 2011. Scipionyx samniticus (Theropoda: Compsognathidae) from the Lower Cretaceous of Italy: osteology, ontogenetic assessment, phylogeny, soft tissue anatomy, taphonomy and palaeobiology. Memorie della Società Italiana di Scienze Naturali e del Museo Civico di Storia Naturale di Milano 37 (1): 1-281.

Domínguez Alonso, P., Milner, A. C., Ketcham, R. A., Cookson, M. J. and Rowe, T. B. 2004. The avian nature of the brain and inner ear of Archaeopteryx. Nature 430 (7000): 666669.

Dufeau, D. L. 2003. The cranial anatomy of the theropod dinosaur Shuvuuia deserti (Coelurosauria: Alvarezsauridae), and its bearing upon coelurosaurian phylogeny. MSc. Dissertation, University of Texas, Austin, Texas, 275pp.

Dufeau, D. L. 2011. The Evolution of Cranial Pneumaticity in Archosauria: Patterns of Paratympanic Sinus Development. Ph.D. Dissertation, Ohio University, Athens, Ohio, USA, 175pp.

Eddy, D. R. and Clarke, J. A. 2011. New information on the cranial anatomy of Acrocanthosaurus atokensis and its implications for the phylogeny of Allosauroidea (Dinosauria: Theropoda). PLoS ONE 6 (3): e17932.

Elzanowski, A. and Stidham, T. A. 2010. Morphology of the quadrate in the Eocene anseriform Presbyornis and extant galloanserine birds. Journal of Morphology 271 (3): 305-323.

Elzanowski, A., Paul, G. S. and Stidham, T. A. 2001. An avian quadrate from the Late Cretaceous Lance formation of Wyoming. Journal of Vertebrate Paleontology 20 (4): $712-719$.

Fisher, H. I. 1955. Some aspects of the kinetics in the jaws of birds. The Wilson Bulletin 67 (3): $175-188$.

Foth, C., Tischlinger, H. and Rauhut, O. W. M. 2014. New specimen of Archaeopteryx provides insights into the evolution of pennaceous feathers. Nature 511 (7507): 79-82.

Fuchs, A. 1954. On the correlation between the skull structure and the muscles in the male Phasianus colchicus $\mathrm{L}$. IV. The attachment of the musculus protractor quadrati et pterygoidei and of the musculus depressor mandibulae. Koninklige Nederlandse Akademie van Wetenschappen, Proceedings, C 57: 666-672.

Gauthier, J. 1986. Saurischian monophyly and the origin of birds. In: Padian, K. (ed.), The Origin of Birds and the Evolution of Flight, Vol. 8, 1-55. Memoirs of the California Academy of Sciences, San Francisco, California. 
967

968

969

970

971

972

973

974

975

976

977

978

979

980

981

982

983

984

985

986

987

988

989

990

991

992

993

994

995

996

997

998

999

1000

1001

1002

1003

1004

1005

1006

1007

1008

1009

1010

1011
Gold, M. E. L., Brusatte, S. and Norell, M. A. 2013. The cranial pneumatic sinuses of the tyrannosaurid Alioramus (Dinosauria, Theropoda) and the evolution of cranial pneumaticity in theropod dinosaurs. American Museum Novitates 3790: 1-46.

Gussekloo, S. W. S. and Bout, R. G. 2005. Cranial kinesis in palaeognathous birds. Journal of Experimental Biology 208 (17): 3409-3419.

Harris, J. D. 2004. Confusing dinosaurs with mammals: Tetrapod phylogenetics and anatomical terminology in the world of homology. The Anatomical Record Part A: Discoveries in Molecular, Cellular, and Evolutionary Biology 281A (2): 1240-1246.

Hendrickx, C. and Buffetaut, E. 2008. Functional interpretation of spinosaurid quadrates (Dinosauria: Theropoda) from the Mid-Cretaceous of Morocco. 56th Annual Symposium of Vertebrate Palaeontology and Comparative Anatomy. Dublin (September 2nd-6th 2008): 25-26.

Hendrickx, C. and Mateus, O. 2014. Torvosaurus gurneyi n. sp., the largest terrestrial predator from Europe, and a proposed terminology of the maxilla anatomy in nonavian theropods. PLoS ONE 9 (3): e88905.

Hendrickx, C., Mateus, O. and Araújo, R. in press. A proposed terminology of theropod teeth (Saurischia: Dinosauria). Journal of Vertebrate Paleontology.

Hendrickx, C., Araújo, R. and Mateus, O. 2014. The nonavian theropod quadrate II: systematic usefulness, major trends and cladistic and phylogenetic morphometrics analyses. PeerJ PrePrints: 2:e380v1.

Hendrickx, C., Hartman, S. A. and Mateus, O. 2015. An overview of non-avian theropod discoveries and classification. PalArch's Journal of Vertebrate Palaeontology 12 (1): 173.

Hoese, W. J. and Westneat, M. W. 1996. Biomechanics of cranial kinesis in birds: testing linkage models in the white-throated sparrow (Zonotrichia albicollis). Journal of Morphology 227 (3): 305-320.

Holliday, C. M. and Witmer, L. M. 2008. Cranial kinesis in dinosaurs: intracranial joints, protractor muscles, and their significance for cranial evolution and function in diapsids. Journal of Vertebrate Paleontology 28 (4): 1073-1088.

Holtz, T. R. J. 1998. A new phylogeny of the carnivorous dinosaurs. Gaia 15: 5-61.

Holtz, T. R. J. 2003. Dinosaur predation: evidence and ecomorphology. In: Kelley, P. H., Kowalewski, M. and Hansen, T. A. (eds.), Predator-Prey Interactions in the Fossil Record, Vol. 20, 325-340. Kluwer Academic/Plenum Publishers, New York.

Holtz, T. R. J., Molnar, R. E. and Currie, P. J. 2004. Basal Tetanurae. In: Weishampel, D. B., Dodson, P. and Osmólska, H. (eds.), The Dinosauria. Second Edition, 71-110. University of California Press, Berkeley, California.

Hone, D. W. E. and Rauhut, O. W. M. 2010. Feeding behaviour and bone utilization by theropod dinosaurs. Lethaia 43 (2): 232-244.

ICVGAN. 2012. Nomina Anatomica Veterinaria. International Committee on Veterinary Gross Anatomical Nomenclature (ICVGAN), 160pp.

Kobayashi, Y. and Lü, J.-C. 2003. A new ornithomimid dinosaur with gregarious habits from the Late Cretaceous of China. Acta Palaeontologica Polonica 48 (2): 235-259.

Kobayashi, Y. and Barsbold, R. 2005. Reexamination of a primitive ornithomimosaur, Garudimimus brevipes Barsbold, 1981 (Dinosauria: Theropoda), from the Late Cretaceous of Mongolia. Canadian Journal of Earth Sciences 42 (9): 1501-1521. 
1012 Kundrát, M. and Janáček, J. 2007. Cranial pneumatization and auditory perceptions of the

1013

1014

1015

1016

1017

1018

1019

1020

1021

1022

1023

1024

1025

1026

1027

1028

1029

1030

1031

1032

1033

1034

1035

1036

1037

1038

1039

1040

1041

1042

1043

1044

1045

1046

1047

1048

1049

1050

1051

1052

1053

1054

1055

1056

oviraptorid dinosaur Conchoraptor gracilis (Theropoda, Maniraptora) from the Late Cretaceous of Mongolia. Naturwissenschaften 94 (9): 769-778.

Larson, P. 2013. The case for Nanotyrannus. In: Parrish, J. M., Molnar, R. E., Currie, P. J. and Koppelhus, E. B. (eds.), Tyrannosaurid Paleobiology, 15-53. Indiana University Press, Bloomington, Indiana.

Larson, P. L. 2008. Atlas of the skull bones of Tyrannosaurus rex. In: Larson, P. L. and Carpenter, K. (eds.), Tyrannosaurus Rex, the Tyrant King, 233-243. Indiana University Press, Bloomington, Indiana.

Lautenschlager, S., Witmer, L. M., Altangerel, P., Zanno, L. E. and Rayfield, E. J. 2014. Cranial anatomy of Erlikosaurus andrewsi (Dinosauria, Therizinosauria): new insights based on digital reconstruction. Journal of Vertebrate Paleontology 34 (6): 1263-1291.

Liyong, J., Jun, C. and Godefroit, P. 2012. A new basal ornithomimosaur (Dinosauria: Theropoda) from the Early Cretaceous Yixian Formation, Northeast China. In: Godefroit, P. (ed.), Bernissart Dinosaurs and Early Cretaceous Terrestrial Ecosystems, 466-487. Indiana University Press, Bloomington, Indiana.

Loewen, M. A. 2010. Variation in the Late Jurassic theropod dinosaur Allosaurus: Ontogenetic, functional, and taxonomic implications. Ph.D. Dissertation, The University of Utah, Texas, Utah, USA, 326pp.

Lowe, P. R. 1926. More notes on the quadrate as a factor in avian classification. Ibis 68 (1): 152188.

Lü, J. 2003. A new oviraptorosaurid (Theropoda: Oviraptorosauria) from the Late Cretaceous of southern China. Journal of Vertebrate Paleontology 22 (4): 871-875.

Lü, J. 2005. Oviraptorid dinosaurs from southern China. Ph.D. Dissertation, Southern Methodist University, Dallas, Texas, USA, 200pp.

Lü, J., Tomida, Y., Azunia, Y., Dong, Z. and Lee, Y. N. 2004. New oviraptorid dinosaur (Dinosauria: Oviraptorosauria) from the Nemegt Formation of Southwestern Mongolia. Bulletin of the National Science Museum: Geology \& paleontology 30: 95-130.

Lü, J. C., Tomida, Y., Azuma, Y., Dong, Z. M. and Lee, Y. N. 2005. Nemegtomaia gen. nov., a replacement name for the oviraptorosaurian dinosaur Nemegtia Lu et al., 2004, a preoccupied name. Bulletin of the National Science Museum of Tokyo, Series C 31: 51.

Madsen, J. H. 1976. Allosaurus fragilis: A revised osteology. Utah Geological Survey Bulletin 109: 1-177.

Madsen, J. H. and Welles, S. P. 2000. Ceratosaurus (Dinosauria, Theropoda): a revised osteology. Utah Geological Survey, Miscellaneous Publication 00-2: 1-89.

Makovicky, P. J., Apesteguía, S. and Agnolín, F. L. 2005. The earliest dromaeosaurid theropod from South America. Nature 437 (7061): 1007-1011.

Maryańska, T. and Osmólska, H. 1997. The quadrate of oviraptorid dinosaurs. Acta Palaeontologica Polonica 42 (3): 361-371.

Meekangvan, P., Barhorst, A., Burton, T. D., Chatterjee, S. and Schovanec, L. 2006. Nonlinear dynamical model and response of avian cranial kinesis. Journal of Theoretical Biology 240 (1): 32-47.

Metzger, K. 2002. Cranial kinesis in lepidosaurs: skulls in motion. In: Aerts, P., D’Août, K., Herrel, A. and Van Damme, R. (eds.), Topics in Functional and Ecological Vertebrate Morphology, 15-46. Shaker Publishing, Maastricht. 
1057

1058

1059

1060

1061

1062

1063

1064

1065

1066

1067

1068

1069

1070

1071

1072

1073

1074

1075

1076

1077

1078

1079

1080

1081

1082

1083

1084

1085

1086

1087

1088

1089

1090

1091

1092

1093

1094

1095

1096

1097

1098

1099

1100

1101

1102

Molnar, R. E. 1991. The cranial morphology of Tyrannosaurus rex. Palaeontographica Abteilung A 217 (4-6): 137-176.

Molnar, R. E. 1998. Mechanical factors in the design of the skull of Tyrannosaurus rex (Osborn, 1905). Gaia 15: 193-218.

Nitzsch, C. L. 1816. Über die bewegung des oberkiefers der vögel. Deutsches Archiv für die Physiologie 2: 361-380.

Norell, M. A., Clark, J. M., Turner, A. H., Makovicky, P. J., Barsbold, R. and Rowe, T. 2006. A new dromaeosaurid theropod from Ukhaa Tolgod (Ömnögov, Mongolia). American Museum Novitates 3545: 1-51.

Norell, M. A., Makovicky, P. J., Bever, G. S., Balanoff, A. M., Clark, J. M., Barsbold, R. and Rowe, T. 2009. A review of the Mongolian Cretaceous dinosaur Saurornithoides (Troodontidae: Theropoda). American Museum Novitates 3654: 1-63.

Novas, F. E., Agnolín, F. L., Ezcurra, M. D., Porfiri, J. and Canale, J. I. 2013. Evolution of the carnivorous dinosaurs during the Cretaceous: The evidence from Patagonia. Cretaceous Research 45: 174-215.

Ortega, F., Escaso, F. and Sanz, J. L. 2010. A bizarre, humped Carcharodontosauria (Theropoda) from the Lower Cretaceous of Spain. Nature 467 (7312): 203-206.

Perle, A., Chiappe, L. M. and Barsbold, R. 1994. Skeletal morphology of Mononykus olecranus (Theropoda: Avialae) from the Late Cretaceous of Mongolia. American Museum Novitates 3105: 1-29.

Rauhut, O. W. M. 2003. The interrelationships and evolution of basal theropod dinosaurs. Special Papers in Palaeontology 69: 1-213.

Rauhut, O. W. M., Milner, A. C. and Moore-Fay, S. 2010. Cranial osteology and phylogenetic position of the theropod dinosaur Proceratosaurus bradleyi (Woodward, 1910) from the Middle Jurassic of England. Zoological Journal of the Linnean Society 158 (1): 155-195.

Rayfield, E. J. 2005. Using finite-element analysis to investigate suture morphology: A case study using large carnivorous dinosaurs. The Anatomical Record Part A: Discoveries in Molecular, Cellular, and Evolutionary Biology 283A (2): 349-365.

Reichert, K. B. 1837. Über die Visceralbogen der Wirbelthiere im allgemeinen und deren Metamorphosen bei den Vögeln und Säugethieren. Archiv für Anatomie, Physiologie, und wissenschaftliche Medizin 1837: 120-222.

Rieppel, O. 2006. The merits of similarity reconsidered. Systematics and Biodiversity 4 (2): $137-$ 147.

Romer, A. 1956. Osteology of the Reptiles. University of Chicago Press, Chicago, 772pp.

Russell, D. A. 1972. Ostrich dinosaurs from the Late Cretaceous of Western Canada. Canadian Journal of Earth Sciences 9 (4): 375-402.

Sadleir, R., Barrett, P. M. and Powell, H. P. 2008. The anatomy and systematics of Eustreptospondylus oxoniensis, a theropod dinosaur from the Middle Jurassic of Oxfordshire, England. Monograph of the Palaeontographical Society, London 160: 1-82.

Samejima, M. and Otsuka, J. 1987. Observations on the Quadrate of Birds. Japanese Journal of Ornithology 35 (4): 129-144.

Sampson, S. D. and Witmer, L. M. 2007. Craniofacial anatomy of Majungasaurus crenatissimus (Theropoda: Abelisauridae) from the Late Cretaceous of Madagascar. Society of Vertebrate Paleontology Memoir 8: 32-104.

Sanders, R. K. and Smith, D. K. 2005. The endocranium of the theropod dinosaur Ceratosaurus studied with computed tomography. Acta Palaeontologica Polonica 50 (3): 601. 
1103

1104

1105

1106

1107

1108

1109

1110

1111

1112

1113

1114

1115

1116

1117

1118

1119

1120

1121

1122

1123

1124

1125

1126

1127

1128

1129

1130

1131

1132

1133

1134

1135

1136

1137

1138

1139

1140

1141

1142

1143

1144

1145

1146

Schwarz, D., Frey, E. and Meyer, C. A. 2007. Pneumaticity and soft-tissue reconstructions in the neck of diplodocid and dicraeosaurid sauropods. Acta Palaeontologica Polonica 52 (1): 167.

Sedlmayr, J. C. 2002. Anatomy, evolution, and functional significance of cephalic vasculature in Archosauria. Ph.D. Dissertation, Ohio University, Athens, Ohio, USA, 398pp.

Sereno, P. C. 2001. Alvarezsaurids: birds or ornithomimosaurs. In: Gauthier, J. and Gall, L. F. (eds.), New Perspectives on the Origin and Early Evolution of Birds: Proceedings of the International Symposium in Honor of John H. Ostrom, 69-98. Yale Univ Peabody Museum.

Sereno, P. C. and Novas, F. E. 1994. The skull and neck of the basal theropod Herrerasaurus ischigualastensis. Journal of Vertebrate Paleontology 13 (4): 451-476.

Sereno, P. C., Martinez, R. N., Wilson, J. A., Varricchio, D. J., Alcober, O. A. and Larsson, H. C. E. 2008. Evidence for avian intrathoracic air sacs in a new predatory dinosaur from Argentina. PLoS ONE 3 (9): e3303.

Sereno, P. C., Beck, A. L., Dutheil, D. B., Gado, B., Larsson, H. C. E., Lyon, G. H., Marcot, J. D., Rauhut, O. W. M., Sadleir, R. W., Sidor, C. A., Varricchio, D. D., Wilson, G. P. and Wilson, J. A. 1998. A long-snouted predatory dinosaur from Africa and the evolution of spinosaurids. Science 282 (5392): 1298-1302.

Smith, D. 1992. The type specimen of Oviraptor philoceratops, a theropod dinosaur from the Upper Cretaceous of Mongolia. Neues Jahrbuch für Geologie und Paläontologie, Abhandlungen 186 (3): 365-388.

Smith, N. D., Makovicky, P. J., Hammer, W. R. and Currie, P. J. 2007. Osteology of Cryolophosaurus ellioti (Dinosauria: Theropoda) from the Early Jurassic of Antarctica and implications for early theropod evolution. Zoological Journal of the Linnean Society 151 (2): $377-421$.

Tahara, R. and Larsson, H. C. E. 2011. Cranial pneumatic anatomy of Ornithomimus edmontonicus (Ornithomimidae: Theropoda). Journal of Vertebrate Paleontology 31 (1): $127-143$.

Takechi, M. and Kuratani, S. 2010. History of studies on mammalian middle ear evolution: A comparative morphological and developmental biology perspective. Journal of Experimental Zoology Part B: Molecular and Developmental Evolution 314B (6): 417433.

Therrien, F., Henderson, D. M. and Ruff, C. B. 2005. Bite me: biomechanical models of theropod mandibles and implications for feeding behavior. In: Carpenter, K. (ed.), The Carnivorous Dinosaurs, 179-237. Indiana University Press, Bloomington, Indiana.

Tsuihiji, T., Barsbold, R., Watabe, M., Tsogtbaatar, K., Chinzorig, T., Fujiyama, Y. and Suzuki, S. 2014. An exquisitely preserved troodontid theropod with new information on the palatal structure from the Upper Cretaceous of Mongolia. Naturwissenschaften 101 (2): $131-142$.

Turner, A. H., Hwang, S. H. and Norell, M. A. 2007. A small derived theropod from Öösh, Early Cretaceous, Baykhangor Mongolia. American Museum Novitates 3557: 1-27.

Turner, A. H., Pol, D. and Norell, M. A. 2011. Anatomy of Mahakala omnogovae (Theropoda: Dromaeosauridae), Tögrögiin Shiree, Mongolia. American Museum Novitates 3722: 166. 
1147

1148

1149

1150

1151

1152

1153

1154

1155

1156

1157

1158

1159

1160

1161

1162

1163

1164

1165

1166

1167

1168

1169

1170

1171

1172

1173

1174

1175

1176

1177

1178

1179

1180

1181

1182

1183

1184

1185

1186

1187

1188

1189

1190

1191

1192
Turner, A. H., Makovicky, P. J. and Norell, M. 2012. A review of dromaeosaurid systematics and paravian phylogeny. Bulletin of the American Museum of Natural History 371: 1206.

Tykoski, R. S. 2005. Anatomy, ontogeny, and phylogeny of coelophysoid theropods. Ph.D. Dissertation, The University of Texas, Austin, Texas, 553pp.

Varricchio, D. J. 1997. Troodontidae. In: Currie, P. J. and Padian, K. (eds.), Encyclopedia of Dinosaurs, 749-754. Academic Press, San Diego, California.

Vickers-Rich, P., Chiappe, L. M. and Kurzanov, S. 2002. The enigmatic birdlike dinosaur Avimimus portentosus. In: Chiappe, L. M. and Witmer, L. M. (eds.), Mesozoic Birds: Above the Heads of Dinosaurs, 65-86. University of California Press, Berkeley/Los Angeles/London.

Welles, S. P. 1984. Dilophosaurus wetherilli (Dinosauria, Theropoda). Osteology and comparisons. Palaeontographica Abteilung A 185 (4-6): 85-180.

Wilson, J. A. 1999. A nomenclature for vertebral laminae in sauropods and other saurischian dinosaurs. Journal of Vertebrate Paleontology 19 (4): 639-653.

Wilson, J. A. 2006. Anatomical nomenclature of fossil vertebrates: standardized terms or 'lingua franca'? Journal of Vertebrate Paleontology 26 (3): 511-518.

Wilson, J. A., D’Emic, M. D., Ikejiri, T., Moacdieh, E. M. and Whitlock, J. A. 2011. A nomenclature for vertebral fossae in sauropods and other saurischian dinosaurs. PLoS ONE 6 (2): e17114.

Witmer, L. M. 1990. The craniofacial air sac system of Mesozoic birds (Aves). Zoological Journal of the Linnean Society 100 (4): 327-378.

Witmer, L. M. 1997. The evolution of the antorbital cavity of archosaurs: a study in soft-tissue reconstruction in the fossil record with an analysis of the function of pneumaticity. Society of Vertebrate Paleontology Memoir 3: 1-76.

Witmer, L. M. and Ridgely, R. C. 2010. The Cleveland tyrannosaur skull (Nanotyrannus or Tyrannosaurus): new findings based on CT scanning, with special reference to the braincase. Kirtlandia 57: 61-81.

Xu, X. and Wu, X.-C. 2001. Cranial morphology of Sinornithosaurus millenii Xu et al. 1999 (Dinosauria: Theropoda: Dromaeosauridae) from the Yixian Formation of Liaoning, China. Canadian Journal of Earth Sciences 38 (12): 1739-1752.

$\mathrm{Xu}, \mathrm{X}$. and Norell, M. A. 2004. A new troodontid dinosaur from China with avian-like sleeping posture. Nature 431 (7010): 838-841.

Xu, X., Norell, M. A., Wang, X., Makovicky, P. J. and Wu, X. 2002. A basal troodontid from the Early Cretaceous of China. Nature 415 (6873): 780-784.

Xu, X., Norell, M. A., Kuang, X., Wang, X., Zhao, Q. and Jia, C. 2004. Basal tyrannosauroids from China and evidence for protofeathers in tyrannosauroids. Nature 431 (7009): 680684.

Zanno, L. E. 2010. Osteology of Falcarius utahensis (Dinosauria: Theropoda): characterizing the anatomy of basal therizinosaurs. Zoological Journal of the Linnean Society 158 (1): 196230.

Zanno, L. E. and Makovicky, P. J. 2011. Herbivorous ecomorphology and specialization patterns in theropod dinosaur evolution. Proceedings of the National Academy of Sciences 108 (1): 232-237.

Zusi, R. L. 1984. A functional and evolutionary analysis of rhynchokinesis in birds. Smithsonian Contributions to Zoology 395: 1-40. 
1193 Zusi, R. L. 1993. Patterns of diversity in the avian skull. The skull 2: 391-437.

1194 Zweers, G. A. and Vanden Berge, J. C. 1998. Birds at geological boundaries. Zoology 100: 1831195202.

1196 Zweers, G. A., Vanden Berge, J. C. and Berkhoudt, H. 1997. Evolutionary patterns of avian

1197 trophic diversification. Zoology 100: 25-57.

1198

1199

\section{FIGURE CAPTIONS}

1201 FIGURE 1. Avian and non-avian theropod terminology of the quadrate bone. Left quadrate of

1202 the common ostrich Struthio camelus (NH.11.75; courtesy of Paolo Viscardi) in (A, G) anterior,

1203 (B, H) lateral, (C, I) posterior, (D, J) medial, (E, K) dorsal, and (F, L) ventral views. The ostrich

1204 quadrate is annotated with (A-F) Baumel and Witmer (1993), Elzanowski et al. (2001) and

1205 Elzanowski and Stidham (2010) terminologies, and (G-L) the here proposed terminology for the

1206 non-avian theropod quadrate.

1207

1208 FIGURE 2. Anatomy of non-avian theropod quadrates. Line drawings of the right (A-E)

1209 quadrate of Tsaagan mangas (IGM 100-1015) in (A) anterior, (B) lateral, (C) posterior, (D)

1210 medial and (E) ventral views; left $(\mathbf{F}-\mathbf{I})$ and right $(\mathbf{J}-\mathbf{K})$ quadrates $(\mathbf{F})$ of Baryonyx walkeri

1211 (NHM R9951), (G) Aerosteon riocoloradensis (MCNA-PV-3137), (H) an indeterminate

1212 Oviraptoridae (GIN A; Maryańska and Osmólska 1997), (I) Tyrannosaurus rex (BHI 3333;

1213 Larson and Carpenter, 2008), (J) Allosaurus 'jimmadseni' (SMA 0005), and (K) Majungasaurus

1214 crenatissimus (FMNH PR 2100) in (F-I) posterior and (J-K) ventral views. Abbreviations: ain,

1215 anterior intercondylar notch; dqje, dorsal quadratojugal contact; ecc, ectocondyle; enc,

1216 entocondyle; ics, intercondylar sulcus; lpq, lateral process of the quadrate; mar, mandibular

1217 articulation; mfq, medial fossa of the quadrate; oca, otic capitulum; pfl, pterygoid flange; pfq,

1218 posterior fossa of the quadrate; pin, posterior intercondylar notch; ppf, posterior pneumatic 
1219 foramen; $\mathbf{q b}$, quadrate body; $\mathbf{q f}$, quadrate foramen; $\mathbf{q h}$, quadrate head; $\mathbf{q j}$, quadratojugal; $\mathbf{q j p}$,

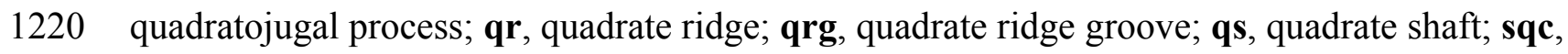

1221 squamosal contact; $\mathbf{s c a}$, squamosal capitulum; vqje, ventral quadratojugal contact; vpdq, ventral

1222 projection of the dorsal quadratojugal contact; vsh, ventral shelf.

1223

1224 FIGURE 3. Topological homologies in the non-averostran theropod quadrate. Left $(\mathbf{A}, \mathbf{C}, \mathbf{F})$ and 1225 right (B, D, E; reversed) quadrates of Dilophosaurus wetherilli (UCMP 37302) in (A) anterior,

1226 (B) lateral, (C) posterior, (D) medial, (E) dorsal and (F) ventral views (courtesy of Randall Irmis

1227 and Matthew Carrano). Right quadrate (G-L; reversed) of Majungasaurus crenatissimus

1228 (FMNH PR 2100) in $(\mathbf{G})$ anterior, $(\mathbf{H})$ lateral, $(\mathbf{I})$ posterior, $(\mathbf{J})$ medial, $(\mathbf{K})$ dorsal, and (L)

1229 ventral views. Left quadrate (M-R) of Baryonyx walkeri (NHM R9951) in (M) anterior, (N)

1230 lateral, (O) posterior, (P) medial, (Q) dorsal, and $(\mathbf{R})$ ventral views. Right quadrate $(\mathbf{S}-\mathbf{W})$ of

1231 Eustreptospondylus oxoniensis (OUMNH J.13558; reversed) in (S) anterior, (T) lateral, (U)

1232 posterior, (V) medial and (W) ventral views (courtesy of Paul Barrett). Abbreviations: afq,

1233 anterior fossa; ain, anterior intercondylar notch; dqje, dorsal quadratojugal contact; ecc,

1234 ectocondyle; enc, entocondyle; ics, intercondylar sulcus; Ipq, lateral process; mfq, medial fossa;

1235 pfq, posterior fossa; pfl, pterygoid flange; qf, quadrate foramen; qh, quadrate head; qjp,

1236 quadratojugal process; qr, quadrate ridge; vpdq, ventral projection of the dorsal quadratojugal

1237 contact; vqje, ventral quadratojugal contact; vsh, ventral shelf of the pterygoid flange.

1238

1239 FIGURE 4. Topological homologies in the non-avian averostran quadrate. Left quadrate (A-F)

1240 of Aerosteon riocoloradensis (MCNA-PV-3137) in (A) anterior, (B) lateral, (C) posterior, (D)

1241 medial, (E) dorsal, and (F) ventral views (courtesy of Martin Ezcurra). Left quadrate (G-K) of 
1242 Alioramus altai (IGM 100-1844) in (G) anterior, (H) lateral, (I) posterior, (J) medial, and (K)

1243 dorsal, (courtesy of Mike Ellison (C AMNH). Right quadrate (L) of Qianzhousaurus sinensis

1244 (GM F10004-1; reversed) in ventral views (courtesy of Stephen Brusatte). Right quadrate (M-Q)

1245 of Falcarius utahensis (UMNH VP 14559; reversed) in (M) anterior, (N) lateral, (O) posterior,

1246 (P) medial, and (Q) ventral views (courtesy of Lindsay Zanno). Left quadrate (R-W) of

1247 Bambiraptor feinbergi (AMNH 30556) in (R) anterior, (S) lateral, (T) posterior, (U) medial, (V)

1248 dorsal, and (W) ventral views. Abbreviations: afq, anterior fossa; dqje, dorsal quadratojugal

1249 contact; ecc, ectocondyle; enc, entocondyle; ics, intercondylar sulcus; lpq, lateral process; mfq,

1250 medial fossa; $\mathbf{m p f}$, medial pneumatic foramen; pfq, posterior fossa; ppf, posterior pneumatic

1251 foramen; pfl, pterygoid flange; qf, quadrate foramen; $\mathbf{q h}$, quadrate head; qjp, quadratojugal

1252 process; qr, quadrate ridge; vpdq, ventral projection of the dorsal quadratojugal contact; vpf,

1253 ventral pneumatic foramen; vqje, ventral quadratojugal contact; vsh, ventral shelf of the

1254 pterygoid flange.

1255

1256 FIGURE 5. Morphology and position of pneumatic openings in the quadrate of non-avian

1257 Theropoda. Right quadrate (A) of the carcharodontosaurid Acrocanthosaurus atokensis (NCSM

1258 14345; reversed) in medial view. Left quadrate (B) of the carcharodontosaurid Mapusaurus

1259 roseae (MCF PVPH-108) in medial view. Left quadrate (C) of the carcharodontosaurid

1260 Giganotosaurus carolinii (MUCPv CH 1) in medial view. Right quadrate (D) of the

1261 therizinosauroid Falcarius utahensis (UMNH VP 14559; reversed) in medial view (courtesy of

1262 Lindsay Zanno). Right quadrate (E) of the metriacanthosaurid Sinraptor dongi (IVPP 10600;

1263 reversed) in posterior view (courtesy of Philip Currie). Left quadrate (F) of the neovenatorid

1264 Aerosteon riocoloradensis (MCNA-PV 3137) in posterior view (courtesy of Martín Ezcurra). 
1265 Left quadrate (G) of the ornithomimid Garudimimus brevipes (IGM 100-13) in posterior view

1266 (courtesy of Yoshitsugu Kobayashi). Right quadrate (H) of the dromaeosaurid Buitreraptor

1267 gonzalezorum (MPCA 245; reversed) in posterior view. Right quadrate (I) of the tyrannosaurid

1268 Alioramus altai (IGM 100-844) in ventral view (courtesy of Mick Ellison). Left quadrate (J) of

1269 the tyrannosaurid Tyrannosaurus rex (FMNH PR2081; cast, reversed) in ventral view. Left

1270 quadrate (K) of the carcharodontosaurid Mapusaurus roseae (MCF PVPH-108) in anterior view.

1271 Left quadrate (L) of the neovenatorid Aerosteon riocoloradensis (MCNA-PV 3137) in lateral

1272 view (courtesy of Martín Ezcurra). Abbreviations: apf, anterior pneumatic foramen; Ipq, lateral

1273 process; Ipfo, lateral pneumatic fossa; mpf, medial pneumatic foramen; ppf, posterior pneumatic

1274 foramen; ppfo, posterior pneumatic fossa; qf, quadrate foramen; vpf, ventral pneumatic foramen.

1275 Scale bars $=10 \mathrm{~cm}(\mathrm{~A}-\mathrm{C}, \mathrm{J}, \mathrm{K}), 5 \mathrm{~cm}(\mathrm{E}-\mathrm{G}, \mathrm{L}), 1 \mathrm{~cm}(\mathrm{D}, \mathrm{H}, \mathrm{I})$.

1276

1277 FIGURE 6. Distribution of quadrate pneumaticity in Theropoda. Cladogram of non-avian

1278 theropods based on the theropod classification summarized by Hendrickx et al. (2015) and

1279 showing the phylogenetic distribution of quadrate pneumaticity and the different quadrate

1280 pneumatic foramina in theropod dinosaurs. Silhouettes by Funkmonk (Dilophosaurus, Shuvuuia

1281 and Dromaeosauroides), M. Martyniuk (Ornitholestes and Similicaudipteryx), T. Michael

1282 Keesey (Deinocheirus and Suzhousaurus), Choiniere et al. (2010; Zuolong; modified) and S.

1283 Hartman (all others).

1284

1285

\section{SUPPLEMENTAL INFORMATION}

1286 - Text S1: Function of quadrate sub-entities and quadrate sub-units terminology. 


\section{1}

Figure 1. Avian and non-avian theropod terminology of the quadrate bone.

Left quadrate of the common ostrich Struthio camelus (NH.11.75; courtesy of Paolo Viscardi)

in $(\mathbf{A}, \mathbf{G})$ anterior, $(\mathbf{B}, \mathbf{H})$ lateral, $(\mathbf{C}, \mathbf{I})$ posterior, $(\mathbf{D}, \mathbf{J})$ medial, $(\mathbf{E}, \mathbf{K})$ dorsal, and $(\mathbf{F}, \mathbf{L})$ ventral views. The ostrich quadrate is annotated with (A-F) Baumel and Witmer (1993) , Elzanowski et al. (2001) and Elzanowski and Stidham (2010) terminologies, and (G-L) the here proposed terminology for the non-avian theropod quadrate. 



\section{2}

Figure 2. Anatomy of non-avian theropod quadrates.

Line drawings of the right (A-E) quadrate of Tsaagan mangas (IGM 100-1015) in (A) anterior, (B) lateral, (C) posterior, (D) medial and (E) ventral views; left (F-I) and right (J-K) quadrates (F) of Baryonyx walkeri (NHM R9951), (G) Aerosteon riocoloradensis (MCNA-PV3137), (H) an indeterminate Oviraptoridae (GIN A; Maryańska and Osmólska 1997) , (I) Tyrannosaurus rex (BHI 3333; Larson and Carpenter, 2008), (J) Allosaurus 'jimmadseni' (SMA 0005), and (K) Majungasaurus crenatissimus (FMNH PR 2100) in (F-I) posterior and (J-K) ventral views. Abbreviations: ain, anterior intercondylar notch; dqjc, dorsal quadratojugal contact; ecc, ectocondyle; enc, entocondyle; ics, intercondylar sulcus; Ipq, lateral process of the quadrate; mar, mandibular articulation; $\mathbf{m f q}$, medial fossa of the quadrate; oca, otic capitulum; pfl, pterygoid flange; pfq, posterior fossa of the quadrate; pin, posterior intercondylar notch; ppf, posterior pneumatic foramen; qb, quadrate body; qf, quadrate foramen; qh, quadrate head; qj, quadratojugal; qjp, quadratojugal process; qr, quadrate ridge; qrg, quadrate ridge groove; qs, quadrate shaft; sqc, squamosal contact; sca, squamosal capitulum; vqjc, ventral quadratojugal contact; vpdq, ventral projection of the dorsal quadratojugal contact; vsh, ventral shelf. 


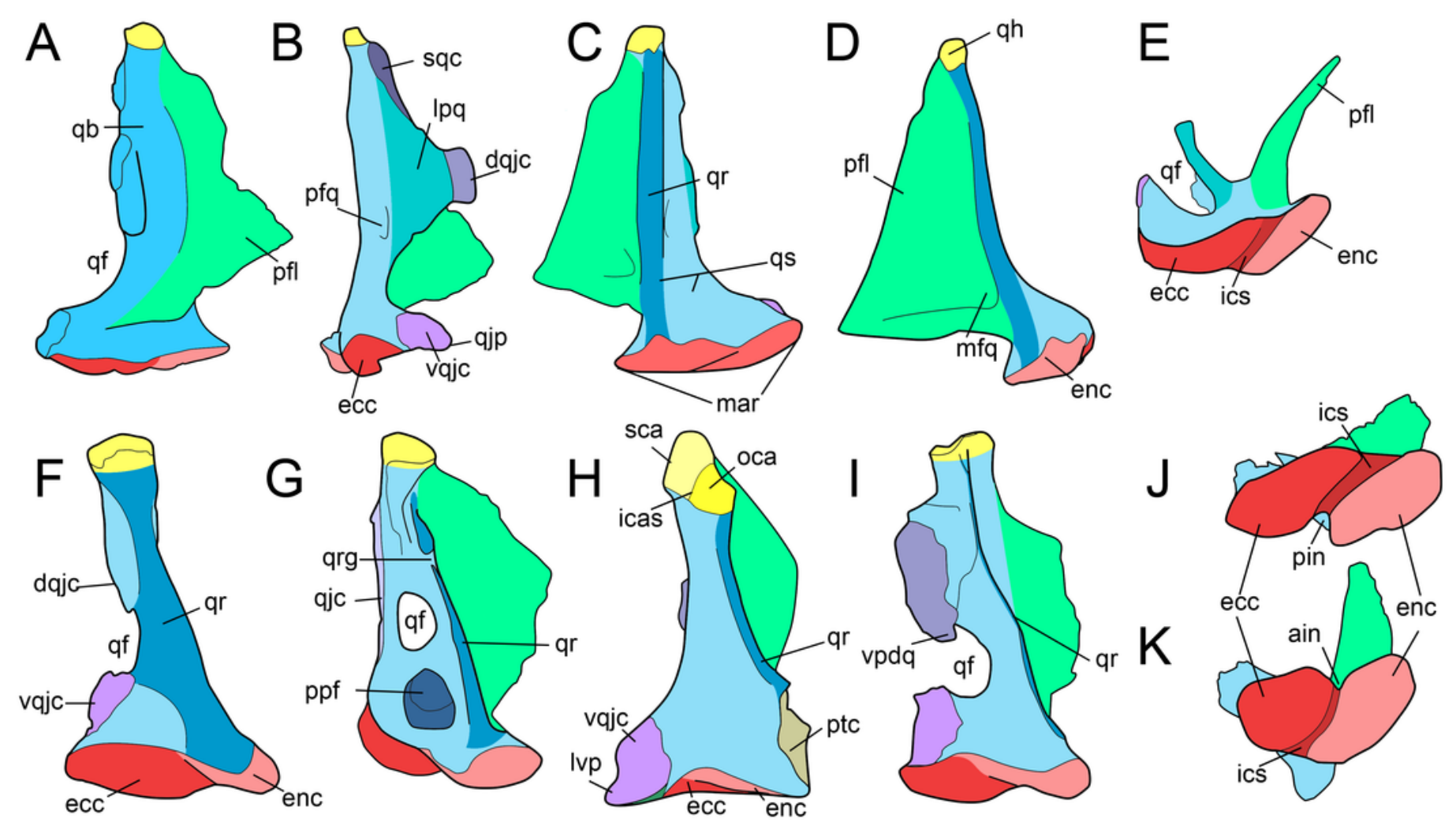




\section{3}

Figure 3. Topological homologies in the non-averostran theropod quadrate.

Left $(\mathbf{A}, \mathbf{C}, \mathbf{F})$ and right (B, D, E; reversed) quadrates of Dilophosaurus wetherilli (UCMP 37302) in (A) anterior, (B) lateral, (C) posterior, (D) medial, (E) dorsal and (F) ventral views (courtesy of Randall Irmis and Matthew Carrano). Right quadrate (G-L; reversed) of Majungasaurus crenatissimus (FMNH PR 2100) in (G) anterior, (H) lateral, (I) posterior, (J) medial, (K) dorsal, and (L) ventral views. Left quadrate (M-R) of Baryonyx walkeri (NHM R9951) in (M) anterior, (N) lateral, (0) posterior, (P) medial, (Q) dorsal, and (R) ventral views. Right quadrate (S-W) of Eustreptospondylus oxoniensis (OUMNH J.13558; reversed) in (S) anterior, (T) lateral, (U) posterior, (V) medial and (W) ventral views (courtesy of Paul Barrett). Abbreviations: afq, anterior fossa; ain, anterior intercondylar notch; dqjc, dorsal quadratojugal contact; ecc, ectocondyle; enc, entocondyle; ics, intercondylar sulcus; Ipq, lateral process; mfq, medial fossa; pfq, posterior fossa; pfl, pterygoid flange; qf, quadrate foramen; qh, quadrate head; qjp, quadratojugal process; qr, quadrate ridge; vpdq, ventral projection of the dorsal quadratojugal contact; vqjc, ventral quadratojugal contact; vsh, ventral shelf of the pterygoid flange. 


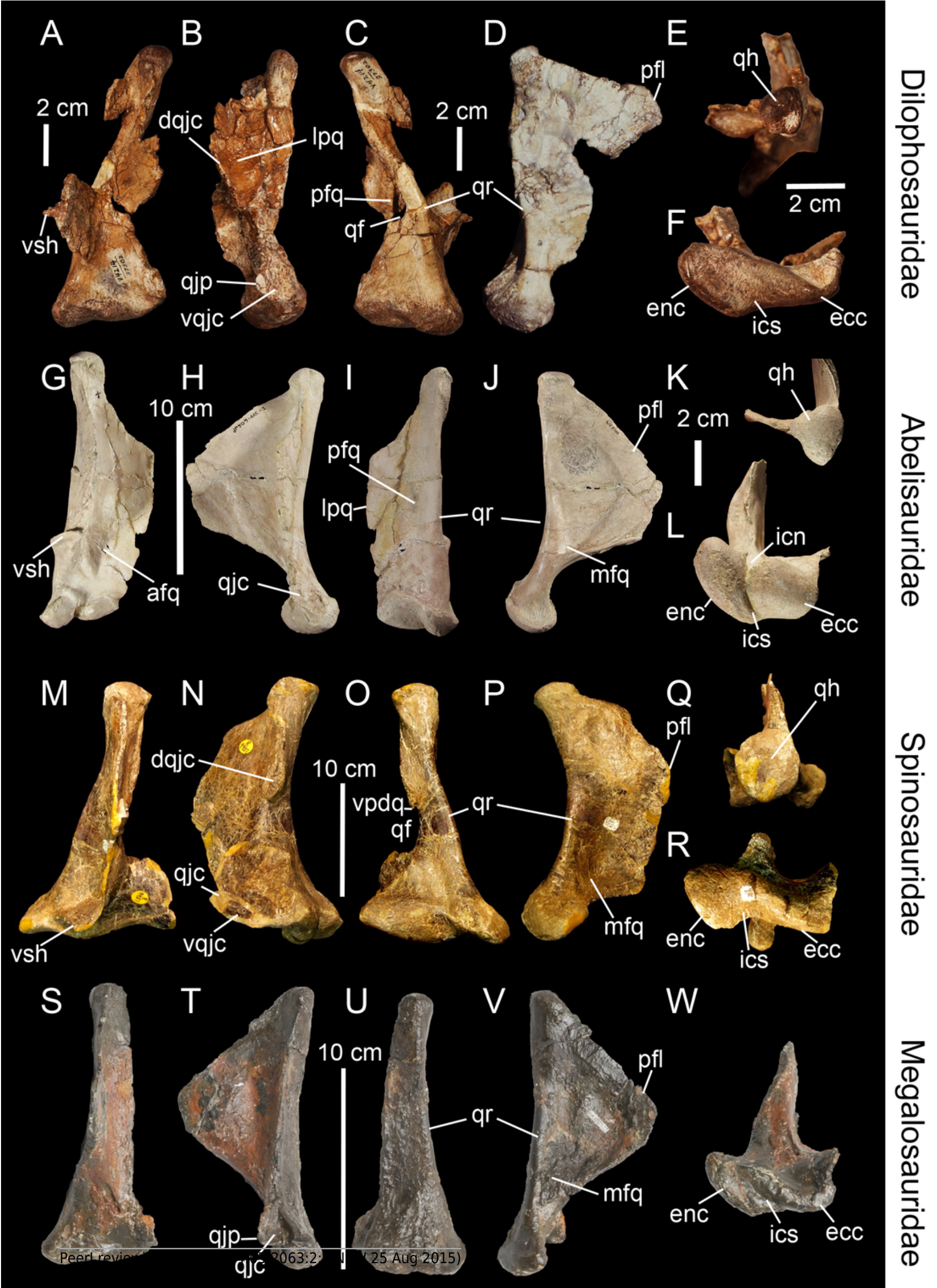




\section{4}

Figure 4. Topological homologies in the non-avian averostran quadrate.

Left quadrate (A-F) of Aerosteon riocoloradensis (MCNA-PV-3137) in (A) anterior, (B) lateral, (C) posterior, (D) medial, (E) dorsal, and (F) ventral views (courtesy of Martin Ezcurra). Left quadrate (G-K) of Alioramus altai (IGM 100-1844) in (G) anterior, (H) lateral, (I) posterior, (J) medial, and (K) dorsal, (courtesy of Mike Ellison $\odot$ AMNH). Right quadrate (L) of Qianzhousaurus sinensis (GM F10004-1; reversed) in ventral views (courtesy of Stephen Brusatte). Right quadrate (M-Q) of Falcarius utahensis (UMNH VP 14559; reversed) in (M) anterior, (N) lateral, (0) posterior, (P) medial, and $(\mathbf{Q})$ ventral views (courtesy of Lindsay Zanno). Left quadrate (R-W) of Bambiraptor feinbergi (AMNH 30556) in (R) anterior, (S) lateral, (T) posterior, (U) medial, (V) dorsal, and (W) ventral views. Abbreviations: afq, anterior fossa; dqjc, dorsal quadratojugal contact; ecc, ectocondyle; enc, entocondyle; icn, intercondylar notch; ics, intercondylar sulcus; Ipq, lateral process; mfq, medial fossa; mpf, medial pneumatic foramen; pfq, posterior fossa; ppf, posterior pneumatic foramen; pfl, pterygoid flange; qf, quadrate foramen; qh, quadrate head; qjp, quadratojugal process; qr, quadrate ridge; vpdq, ventral projection of the dorsal quadratojugal contact; vpf, ventral pneumatic foramen; vqjc, ventral quadratojugal contact; vsh, ventral shelf of the pterygoid flange. 


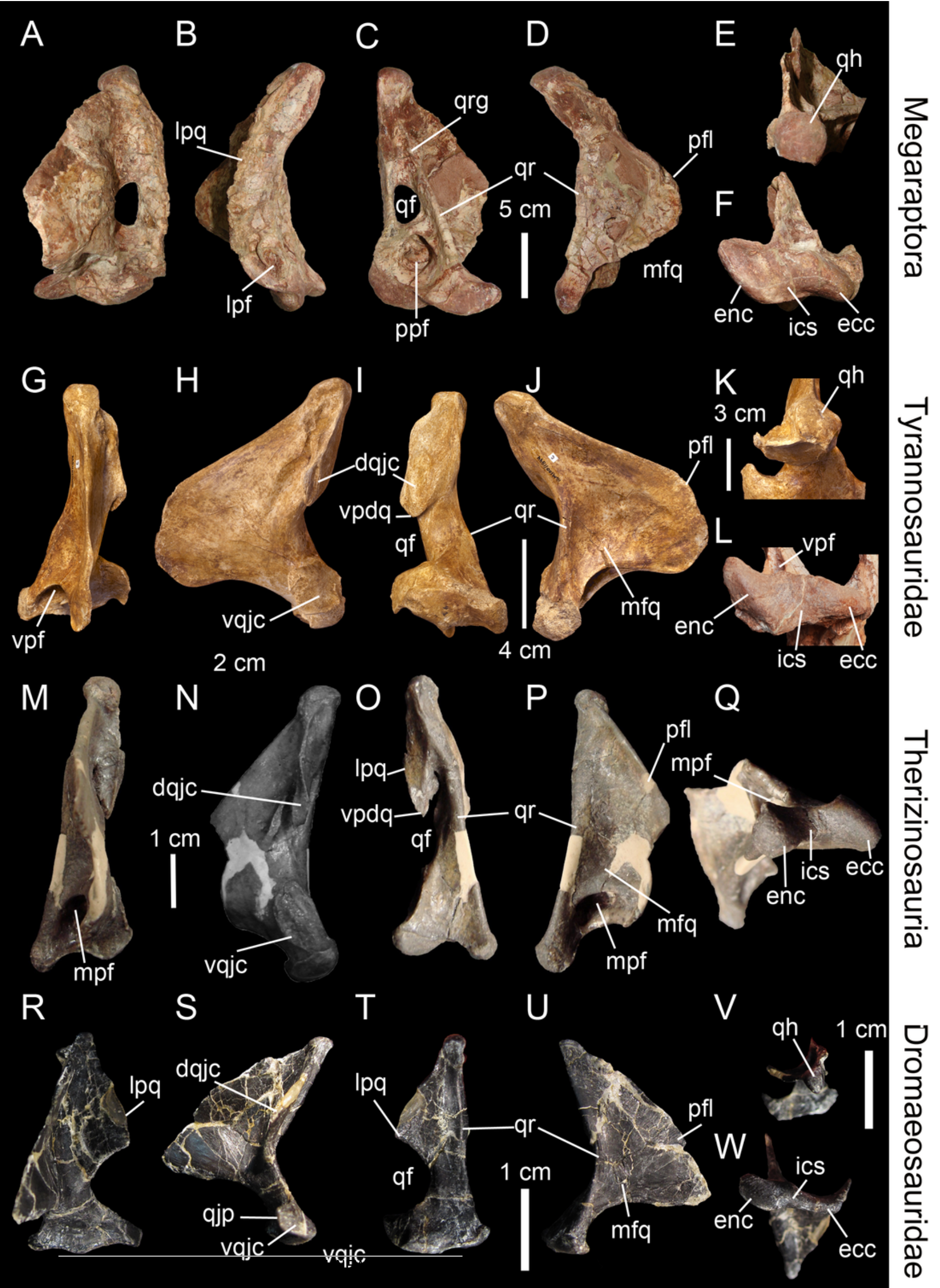




\section{5}

Figure 5. Morphology and position of pneumatic openings in the quadrate of non-avian Theropoda.

Right quadrate (A) of the carcharodontosaurid Acrocanthosaurus atokensis (NCSM 14345; reversed) in medial view. Left quadrate (B) of the carcharodontosaurid Mapusaurus roseae (MCF-PVPH-108) in medial view. Left quadrate (C) of the carcharodontosaurid Giganotosaurus carolinii (MUCPv CH 1) in medial view. Right quadrate (D) of the therizinosauroid Falcarius utahensis (UMNH VP 14559; reversed) in medial view (courtesy of Lindsay Zanno). Right quadrate (E) of the metriacanthosaurid Sinraptor dongi (IVPP 10600; reversed) in posterior view (courtesy of Philip Currie). Left quadrate (F) of the neovenatorid Aerosteon riocoloradensis (MCNA PV 3137) in posterior view (courtesy of Martín Ezcurra). Left quadrate (G) of the ornithomimid Garudimimus brevipes (IGM 100-13) in posterior view (courtesy of Yoshitsugu Kobayashi). Right quadrate $(\mathbf{H})$ of the dromaeosaurid Buitreraptor gonzalezorum (MPCA 245; reversed) in posterior view. Right quadrate (I) of the tyrannosaurid Alioramus altai (IGM 100-844) in ventral view (courtesy of Mick Ellison). Left quadrate (J) of the tyrannosaurid Tyrannosaurus rex (FMNH PR2081; cast, reversed) in ventral view. Left quadrate (K) of the carcharodontosaurid Mapusaurus roseae (MCF-PVPH-108) in anterior view. Left quadrate (L) of the neovenatorid Aerosteon riocoloradensis (MCNA PV 3137) in lateral view (courtesy of Martín Ezcurra). Abbreviations: apf, anterior pneumatic foramen; Ipq, lateral process; Ipf, lateral pneumatic foramen; mpf, medial pneumatic foramen; ppf, posterior pneumatic foramen; ppfo, posterior pneumatic fossa; qf, quadrate foramen; vpf, ventral pneumatic foramen. Scale bars $=10 \mathrm{~cm}(A-C, J, K), 5 \mathrm{~cm}(E-G, L), 1 \mathrm{~cm}(D, H, I)$. 
PeerJ Reviewing Manuscript

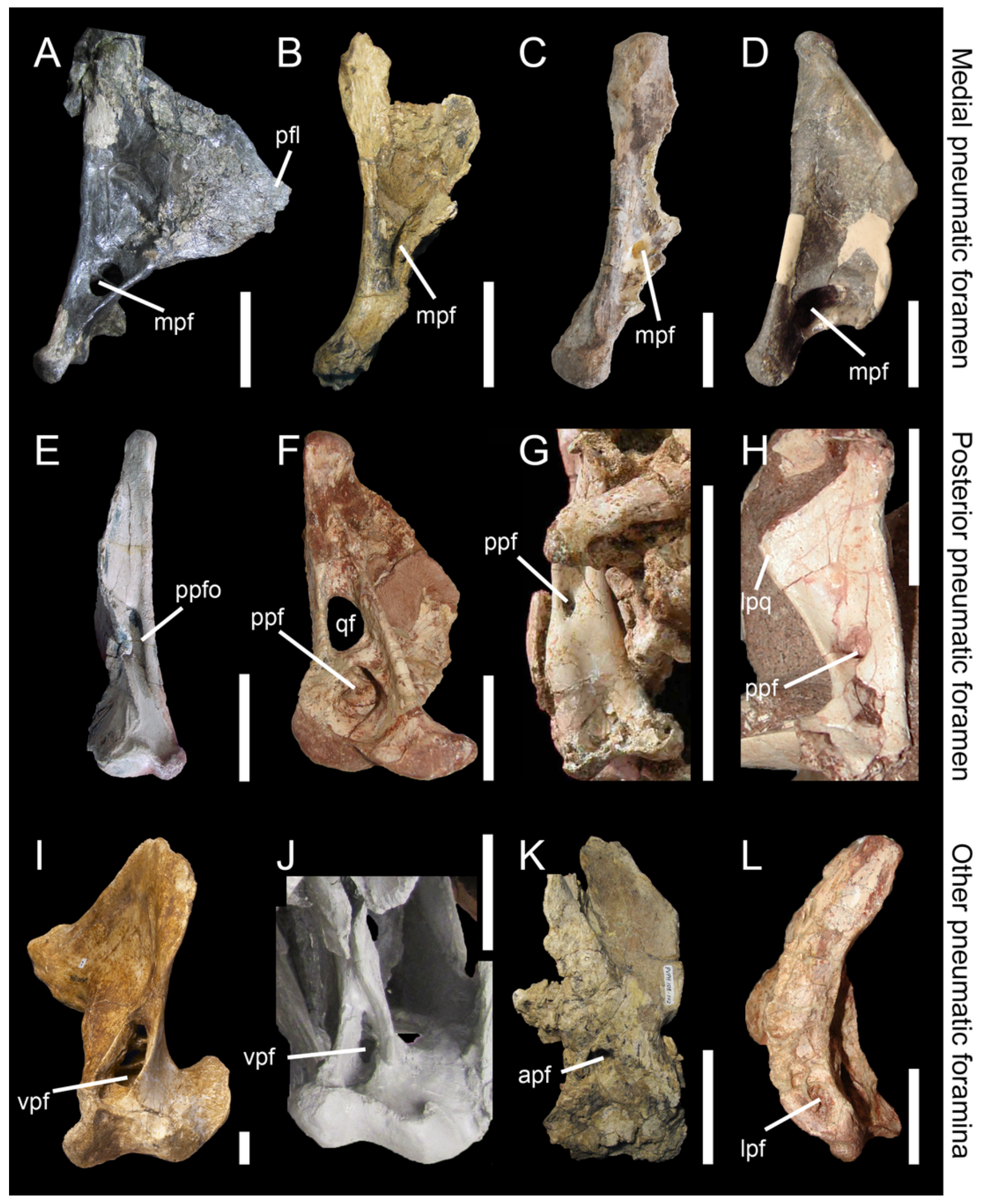




\section{6}

Figure 6. Distribution of quadrate pneumaticity in Theropoda.

Cladogram of non-avian theropods based on the theropod classification summarized by Hendrickx et al. (in pressa) and showing the phylogenetic distribution of quadrate pneumaticity and the different quadrate pneumatic foramina in theropod dinosaurs. Silhouettes by Funkmonk (Dilophosaurus, Shuvuuia and Dromaeosauroides), M. Martyniuk (Ornitholestes and Similicaudipteryx), T. Michael Keesey (Deinocheirus and Suzhousaurus), Choiniere et al. (2010 ; Zuolong; modified) and S. Hartman (all others). 


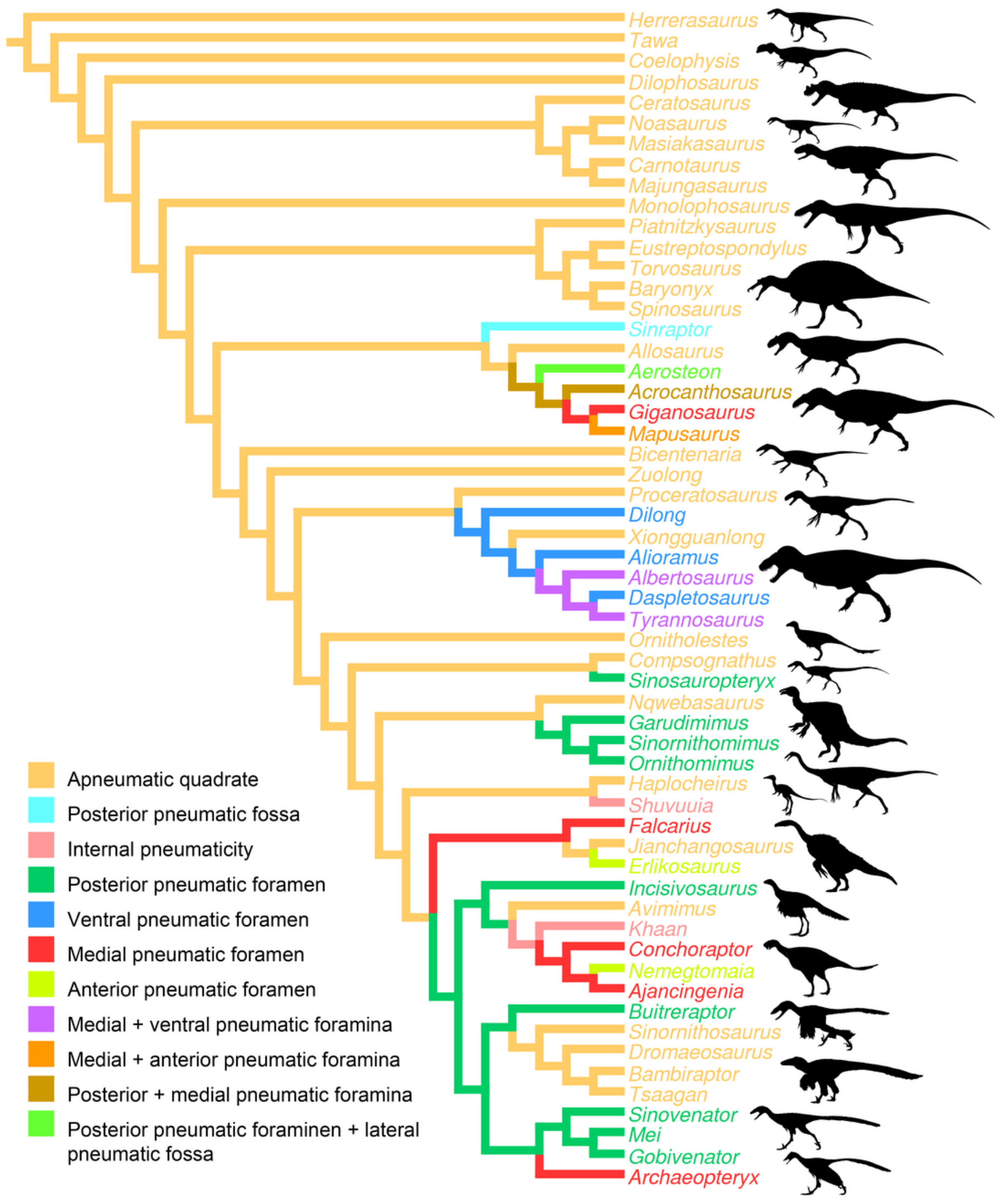




\section{Table $\mathbf{1}$ (on next page)}

Table 1.

Standardized terminology and abbreviation of the non-avian theropod quadrate and comparison with the terminology of the avian quadrate based on Baumel and Witmer (1993) , Elzanowski et al. (2001) and Elzanowski and (Stidham 2010) . 
1 TABLE 1. Standardized terminology and abbreviation of the non-avian theropod quadrate and

2 comparison with the terminology of the avian quadrate based on Baumel and Witmer (1993),

3 Elzanowski et al. (2001) and Elzanowski and (Stidham 2010).

\begin{tabular}{ll|l}
\hline Non-avian theropod quadrate & & Avian theropod quadrate \\
\hline Quadrate & $\mathrm{q}$ & Os quadratum (Quadratum) \\
Quadrate body & $\mathrm{qb}$ & Corpus quadrati \\
Quadrate shaft & $\mathrm{qs}$ & $/$ \\
Quadrate ridge & $\mathrm{qr}$ & $/$ \\
Quadrate ridge groove & $\mathrm{qrg}$ & $/$ \\
Quadrate foramen & $\mathrm{qf}$ & $/$ \\
Lateral process & lpq & $/$ \\
Quadratojugal contact & qjc & Cotyla quadratojugalis \\
Ventral quadratojugal contact & vqjc & $/$ \\
Dorsal quadratojugal contact & $\mathrm{dqjc}$ & $/$ \\
Quadratojugal process & qjp & $/$ \\
Ventral projection of the & vpdq & $/$ \\
dorsal quadratojugal contact & \\
Dorsal projection of the & dpvq & , \\
ventral quadratojugal contact & \\
Squamosal contact & sqc & $/$ \\
Posterior fossa & pfq & $/$ \\
Otic capitulum & oca & Capitulum oticum \\
\hline
\end{tabular}




\begin{tabular}{|c|c|c|}
\hline Squamosal capitulum & sca & Capitulum squamosum \\
\hline Intercapitular sulcus & icas & Incisura/Vallecula intercapitularis \\
\hline Mandibular articulation & mar & Pars/Processus mandibularis \\
\hline Ectocondyle & ecc & Condylus (mandibularis) lateralis \\
\hline Entocondyle & enc & Condylus (mandibularis) medialis \\
\hline Mediocondyle & mec & Condylus caudalis \\
\hline Intercondylar sulcus & ics & Sulcus/Vallecula intercondylaris \\
\hline Anterior intercondylar notch & ain & I \\
\hline Posterior intercondylar notch & pin & I \\
\hline Pterygoid flange & $\mathrm{pfl}$ & Processus orbitalis \\
\hline Pterygoid contact & ptc & $\begin{array}{l}\text { Condylus pterygoideus/Facies } \\
\text { articularis pterygoidea }\end{array}$ \\
\hline Medial fossa & $\mathrm{mfq}$ & Fossa basiorbitalis \\
\hline Ventral shelf & vsh & l \\
\hline Quadrate diverticulum & qdi & / \\
\hline Dorsal pneumatic foramen & $\mathrm{dpf}$ & l \\
\hline Medial pneumatic foramen & $\mathrm{mpf}$ & Foramen pneumaticum basiorbitale \\
\hline Posterior pneumatic foramen & ppf & Foramen pneumaticum caudomediale \\
\hline Anterior pneumatic foramen & apf & Foramen pneumaticum rostromedial \\
\hline Ventral pneumatic foramen & vpf & Foramen pneumaticum adventitium \\
\hline Posterior pneumatic fossa & ppfo & / \\
\hline Lateral pneumatic fossa & lpfo & / \\
\hline
\end{tabular}

